\title{
INFORMATION PROCESSING ON THE SWISS STOCK MARKET
}

\author{
Prof. Dr. Manuel Ammann (manuel.ammann@unisg.ch) \\ and Stephan Kessler (stephan.kessler@unisg.ch) \\ Swiss Institute of Banking and Finance \\ University of St. Gallen \\ Rosenbergstr.52, CH - 9000 St. Gallen, Switzerland \\ Tel.: ++41-71-224-7004 \\ Fax: ++41-71-224-7088 \\ We would like to thank Bernd Brommundt, Michael Genser, \\ Ralf Seiz, Michael Verhofen and Rico von Wyss \\ for helpful comments. We are especially grateful \\ to Nicolas Gisiger for valuable research assistance. \\ Furthermore we would like to thank two anonymous referees \\ for helpful comments.
}

\section{Introduction}

The efficiency of capital markets is one of the central issues of financial research. Insider trading and the speed of information processing are important aspects in the evaluation of capital markets and their efficiency. This paper contributes an empirical investigation of insider trading and information processing on the Swiss equity market.

Under the assumption of the semi-strong form of capital market efficiency, all publicly available information is incorporated in market prices and therefore abnormal returns can only be achieved by a trading strategy based on insider information.
A number of studies have been conducted on this topic. Examples are FERREIRA and BROOKS (2000), JENG, METRICK and ZECKHAUSER (1999, 2003), KEOWN and PINKERTON (1981), LAKONISHOK and LEE (1998), MEULBROEK (1992), and SEYHUN (1986, 1988, 1992), among others. In the US equity market, insiders investing in high market-to-book-value firms earn higher returns, as shown by JENG et al. (2003), leading to the hypothesis that there may be a difference between high and low market-to-book-value firms. Most studies investigate US stock markets, where good data is available. If the capital markets are efficient according to the semi-strong form, new information has to be incorporated into the prices immediately upon its release. By using a common event study analysis, it can be tested whether the markets behave according to this assumption. For the US stock market, MORSE (1981) finds a run-up of returns before the release of earnings and BERNARD and THOMAS (1989) find a post-earnings announcement drift in returns. AHARONY and SWARY (1980) find information processing for two days. Furthermore, ATIASE (1985) measures different effects of earnings announcements on the stock price of firms with small and large capitalization.

For the Swiss stock market, studies investigating insider trading and information processing have not been conducted in the context of news releases 
so far. In this study, we therefore investigate information processing and insider trading on the Swiss stock market, using releases of financial statements and announcements of acquisitions. We analyze post-release time periods to investigate the speed of information processing and prerelease periods to test for the potential occurrence of insider trading.

The aspect of insider trading in this study is of special interest because the regulation of insider trading in Switzerland is different from other countries. Insider trading in Switzerland is only forbidden for events that have a serious influence on prices. In the law it is stated that corporate control actions, the emission of new shares, and other events with a potentially high impact on prices belong to these events. Earnings announcements, however, even if they contain important information, such as announcements of severe earnings decline, do not belong to this category. In many cases, corporate control actions of an acquiring company do not belong to this category either. Thus, many insider trading activities are legal in Switzerland. In addition there are no strict reporting laws in Switzerland. Presumably, insiders could take advantage of this regulatory setting. Therefore, this regulatory setting gives a special motivation for an event study as conducted in this paper. Furthermore, the Swiss market is also different from the US market, for which most of the existing studies have been conducted, in several other aspects. For example, it is much smaller, less liquid and less regulated than the US market. The efficiency of the market in processing information could therefore be rather different, in particular with respect to the speed of the process.

In Section 2, we review the previous research on information processing and insider trading. Section 3 gives a brief overview of the economic context of the methodology used in this study. In Section 4, we present the design of this study and describe the test statistics. Section 5 reviews the data and Section 6 describes the empirical results. Section 7 concludes.

\section{Literature Review}

Much empirical work regarding insider trading has been done for the US[1], mainly because the SEC publishes a wide variety of information on the activities of insiders on capital markets that can be used for evaluating different aspects of insider trading.

A paper by SEYHUN (1986) finds significant abnormal positive returns for insider purchases and significant negative returns for insider sales. In smaller firms insiders earn higher returns than in larger firms. Outside investors imitating insiders on the publication or reporting day of the insider transaction to the SEC cannot earn significant abnormal returns. This is consistent with an efficient market. SEYHUN (1988) finds again evidence for significant abnormal returns as a consequence of insider transactions. In a later paper SEYHUN (1992) finds predictive power of insider trading for future stock returns and future economic development. JENG et al. (1999) find that insiders profit more from their purchases than from their sales. This is caused by the fact that sales often reflect a manager's need for liquidity, whereas purchases reflect favorable information. JENG et al. (2003) also find a positive abnormal return on portfolios consisting of stocks purchased by insiders, but no significant abnormal returns for insider sales portfolios. Insiders in high market-to-bookvalue firms earn higher profits with purchases than insiders in low market-to-book-value firms. In contrast to SEYHUN (1986) they have no evidence for the assumption that top executives earn higher returns than other officers and directors. A paper by JAFFE (1974) reports no important effects of regulatory changes on insider trading. This seems to indicate that the results for the US stock market should be valid for other markets as well, including Switzerland, where the regulatory environment is very different from the USA. Other interesting studies dealing with insider trading are written by FERREIRA and BROOKS (2000) and LAKONISHOK and LEE (1998). 
MEULBROEK (1992) looks at illegal insider trading activities - mostly before corporate control actions. Before the announcement on average $42.5 \%$ of the cumulated abnormal returns are realized. Insider trading goes along with abnormally high volume. At least three days before an acquisition CONRAD and NIDEN (1992) find an increased volume and an increased number of transactions in the target stocks. KEOWN and PINKERTON (1981) show significant abnormal returns and higher volume 10 days before the announcement of an aquisition. All these papers take advantage of information on insider trading from the SEC.

Another paper by GIVOLY and PALMON (1985) provides evidence for abnormal profits to insiders as well. They conclude that some of the abnormal return is connected to the revelation of information towards insiders' trades. Using a similar approach than this study, no evidence is found for insiders exploiting news announcements.

A theoretical paper that deals with the effects of insider trading on the markets and welfare implications was written by LELAND (1992). Since insider trading is a complex topic with positive and negative effects on welfare, he does not arrive at clear results with respect to the overall effect of insider trading.

Regarding the impact of news releases on stock prices in general there is a large range of literature available. An early paper by BEAVER (1968) deals with the announcement effect of annual reports. Volume is abnormally low before publication and increases significantly in the announcement week, whereas the average standardized squared residual from the market model is highest in the announcement week. Above-normal activity can also be observed in the two weeks after announcement. This indicates a relatively long information processing period. CHEN et al. (1997) show that the more information is available on a stock, the lower are abnormal returns upon an earnings announcement but the faster is the speed of stock price adjustment. The amount of informa- tion available is highly correlated with size. HILLMER and YU (1979) survey single news events with high-frequency data and find fast information processing with effects on return and volume dying out after 4 to 13 hours. MORSE (1981) studies the effect of earnings announcements. He finds that the abnormal return and volume are at least significantly above normal levels from the publication day until one day after the information is published in the Wall Street Journal. There are also significant abnormal returns during the 10 days before the information release, possibly caused by insider trading. In a paper by LEE et al. (1993), significantly increased volume for the announcement day itself and at least 2 days thereafter is found. Often a post-earnings announcement drift is observed, for which BERNARD and THOMAS (1989) offer an explanation; according to their hypothesis, it is a delayed price response to new information - possibly because of transaction costs. AHARONY and SWARY (1980) and JAIN (1988) study the reactions of stock prices to announcements of changes in dividends and economic statistics, respectively.

\section{Economic Background}

We investigate the behavior of prices and volumes before (possible insider trading) and after (analysis of the speed of information processing) information releases.

It is assumed that the release of price-relevant information has an impact on returns and volumes of trades. After the release of information, equity prices can change and new information is processed into the market price. This process ends in new equilibrium prices of a company's stock. In the course of this process there is increased trading volume because traders adjust their position in a stock according to the new information. The price adjustment itself leads to abnormal returns. According to the semi-strong form of market efficiency this process is fast and no significant ab- 
normal returns can be earned on any publicly available information. This suggests that information processing occurs within a few hours. It is also possible that the old equilibrium price is equal to the new equilibrium price after information release. However, there could be investors buying and selling the stock after publication because of the new information. Then the volume increases through the change of the ownership of the shares, but there is no price change. In such a situation volume is an important indicator for information processing after the publication complementary to returns.[2] This paper aims at evaluating the speed of the information processing in the Swiss market.

Before the new information is released, there is noise of uninformed traders and sometimes informed trading by insiders. It is presumed that some insiders use their special information about future stock movements and position themselves in the market to profit from their knowledge. If insiders buy or sell enough shares, their trades have an impact on the price and the trade volume of the stock. Thus, the presence of insiders might be reflected in the behavior of a company's stock before the release of price-relevant information. On the one hand, the trading volume increases before such an information event as insiders enter the market to profit from their information. This alone is no indication for insider trading because an increasing volume might also be caused by traders who want to position themselves before the information event without possessing any special inside information. Those investors are not able to gain any abnormal profits on average though because it is assumed that any publicly available information is already incorporated in the stock prices. Thus, some of these investors buy a stock while others sell it. In the end there is a higher volume, but the market price stays the same. Insiders, however, think that they know exactly in which direction the prices will move and buy or sell stocks accordingly. This induces a direction into the stock movement.
Therefore, the existence of abnormal returns in a short time window before the information release together with an increased volume is considered to be evidence for insider trades. This assumes, similar to KEOWN and PINKERTON (1981) and MEULBROEK (1992), that the extent of insider trading is large enough to have a measurable impact on returns and trading volume of a stock.

The argument above assumes the semi-strong form of the efficient markets hypothesis. If the strong form of the efficient market hypothesis held, no positive abnormal returns could be generated by trading on insider information. Thus, significant abnormal returns could not be attributed to insiders trying to profit from their inside information.

\section{Study Design}

Our econometric setting follows MACKINLAY (1997). Events occuring at time $\tau$ are identified by evaluating press releases available from the news provider Hugin. Once an event is identified the event window is determined ranging from a number of days before the event (pre-event window) to a number of days after the event (post-event window). The different windows are defined relative to a specific event and have the same length for all events. The event day belongs to none of the windows. The estimation window starts before the event window and ends just one day prior to the pre-event window (PEW). The timeline of this study design is illustrated by Figure 1 .

$\mathrm{T}_{1}$ denotes the first day of the pre-event period. The input parameters, which are needed to perform the hypothesis tests designed to study insider trading and the speed of information processing, are determined from data within the estimation window. The pre-event window is denoted PEW and is $\tau-T_{1}$ days long. If there are statistically significant abnormal returns as well as a volume significantly above average, insider trading is suspected. The post-event period ( $T_{2}-\tau$ days) is used 
Figure 1: Time Line of the Event Study

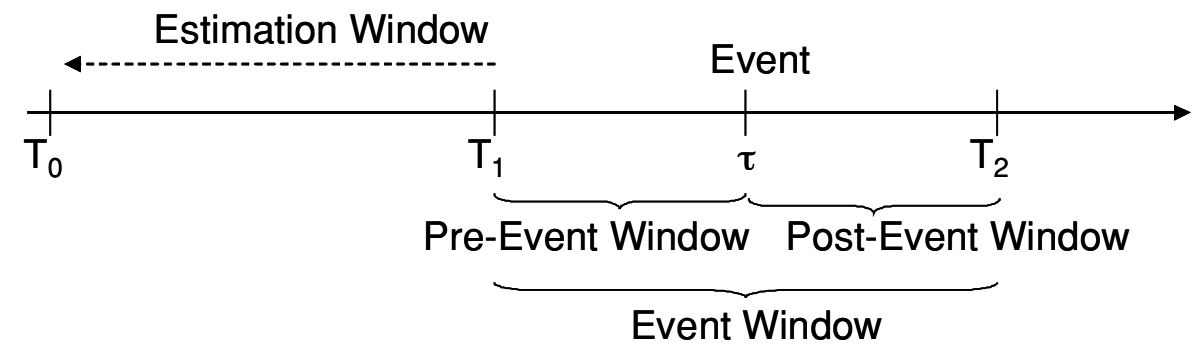

to evaluate the speed of information processing and to compare the behavior of stock returns and volume before as well as after the event.

To identify abnormal returns, we use a market model allowing for the separation of returns into systematic and firm-specific components. A market model of the following form is used:

$R_{i, t}=\alpha_{i}+\beta_{i} R_{M, t}+\varepsilon_{i, t}$

where $R_{i, t}$ denotes the continuously compounded return of the respective stock and $\mathrm{R}_{\mathrm{M}, \mathrm{t}}$ the continuously compounded return of the market upon event $i$ and time $t \in\left[T_{0}, T_{1}\right)$.

The parameters are determined by an OLS regression on data from the estimation window using a time frame of 250 days before the start of the PEW. The parameters for the determination of the abnormal returns are therefore estimated out-ofsample.[3]

The abnormal returns are equal to the residual of the regression, i.e.,

$$
A R_{t, t}=R_{i, t}-\hat{\alpha}_{i}-\hat{\beta}_{i} R_{M, t}
$$

where $\hat{\alpha}_{i}$ and $\hat{\beta}_{i}$ are estimated by the regression and $\mathrm{t} \in\left[\mathrm{T}_{1}, \mathrm{~T}_{2}\right]$. The market model and the abnormal returns are estimated for each event win- dow. This approach only captures the effects of market risk on asset returns. To control for other systematic risk factors, the empirical analysis in this paper is also performed with detrended abnormal returns, but results do not change and are consequently not reported here.

Using the OLS method, the abnormal returns are assumed to be jointly normally distributed with a conditional mean of zero. If there is no insider trading, the abnormal returns in the event window should be only random noise and therefore not significantly different from 0 . Thus, a natural test for insider trading is to test for systematic and significant abnormal returns in the PEW. If there is no insider trading, the event has no impact on the behavior of abnormal returns in the PEW, i.e., the mean of the abnormal returns in the PEW is not significantly different from zero. Using a standard t-test termed $\theta_{1}$ (see appendix for details), we test whether the aggregated abnormal return in the PEW is significantly different from 0 . Obviously, this statistic depends on the length of the PEW. Therefore this window is varied to determine the robustness of results. Constructing another statistic, $\theta_{2}$, we can test whether there are significant abnormal returns on special days before the event. $\theta_{2}$ can also be used to determine how long the information processing in the market takes, i.e., how long after the event the significant daily abnormal 
returns persist. Finally, applying the standard difference test $\theta_{3}$, it is tested whether the cumulative returns in the post-event period are significantly different from the cumulative returns in the preevent period. As the new information is released, the market needs some time to adjust prices. In this study, this period is denoted p. Pre-event and post-event periods are set to the same length. The statistic $\theta_{3}$ is relatively unaffected by possible trends that might bias the other test statistics discussed. The variance in the PEW is calculated assuming that it is equal to the variance in the estimation period. In the context of the release of accounting data this might cause problems due to increased noise trading in the PEW. For the postevent window the variance is calculated from data observations after this window. There are other statistics that do not have this restriction[4], but they have other restrictions - e.g. they have bad convergence characteristics for the small subsamples that are used in this study. Details for the tests can be found in the appendix.

Our data sample contains good and bad news having opposing effects on stock prices. Aggregating those returns to the average cumulative abnormal returns without modification would cancel out the effects of good and bad news, biasing the results towards an inability to discard the null hypothesis of no abnormal returns because of news releases. Therefore, the returns of bad news are multiplied by minus one to allow the evaluation of good and bad events in the same statistic. The multiplication by minus one is not performed when only the negative events are considered.

In capital markets the release of relevant information results in a price change: positive returns for good events and negative returns for bad events. The corresponding price movements take place on the day of the information release and persist, perhaps, until a few days after the release. By evaluating the cumulative abnormal returns on the day of an event and a few days thereafter, the direction of the news can be determined. This period is called Information Processing Period (IPP).
If the cumulated returns in the IPP are positive, the event is considered to be good news. Similarly, negative returns indicate bad news.[5] Note that the IPP has to be distinguished from the time it takes until the information is incorporated into the data. The IPP is chosen solely to classify positive and negative events. It does not directly reflect the time it actually takes to process new information.

Using abnormal returns, we control for market returns. Since there might also be firm-specific trends, the data is detrended in a separate procedure. Detrending, however, does not change the results significantly. To check the stability of the classification, we altered the information processing period from 1 to 8 days (with default at 5 days including release). The overall results are only slightly affected by changing the length of the IPP. Noise in the information processing period might lead to a misclassification of events. The applied procedure also imposes a selection bias on the returns in the post-event window used to examine the speed of information processing. Nonetheless, stress testing has shown our procedure for separating good and bad events to be sufficiently reliable.

Trading volume is also influenced by the processing of information after the event or insider trading before the event. Since volume is supposed to rise due to an event regardless of the news content, there is no need to distinguish between good and bad news: the directional effect on volume is expected to be the same. For volume, two types of tests are applied. The first approach is a t-test, testing for a significant deviation of cumulated volume in the PEW from its mean in the estimation window and is denoted $\theta_{4}$. The null hypothesis of this test statistic is that there is no increased trading volume for all the events considered in the pre-event period (see appendix for details). The second approach uses the non-parametric test statistic $\theta_{5}$. It tests the null hypothesis of no insider trading by checking for pure noise in the pre-event period, meaning that the volume follows the same 
process as in the estimation period. In practice, it tests if the daily volume is more than $50 \%$ of the days in the PEW above its median during the estimation period. This non-parametric statistic is also implemented for trade volume on single days (e.g. the volume on the $7^{\text {th }}$ day before the event) during the event window and is denoted by $\theta_{6}$. The non-parametric test is introduced to control for strongly varying differences in trading volume of the included companies.

Again, volume as a stand-alone measure for insider trading is very problematic because an increase in volume might not only be caused by insiders entering the market, but also because uninformed traders taking different positions before the information event. Thus volume and returns have to be considered together.

To take a look at insider trading more closely, the tests are performed for subsamples. The dataset is split in two parts according to the market value of the companies and according to the market-tobook ratio. The rationale for using the market value is that there might be more insider trading in smaller companies because corporate governance mechanisms might be inforced less stringently.[6] The actions of insiders might also have a greater impact on returns and volume due to the lower overall volume. It is also hypothesized that companies with smaller market capitalization have less media coverage and lower liquidity. Therefore, information processing may take longer.

It is possible that there are events leading to new information about a company without having a large impact on the stock price. It can be assumed that insiders have the ability to evaluate the extent to which the information is already reflected in the price. Taking into account transaction costs, insiders would not trade on all inside information. Rather, they would identify events supposedly resulting in large price movements and exploit their information by taking the respective positions before such events. To control for this effect, we also examine the subset of events that result in large price movements on the day the information is released. We define such events as having abnormal positive returns of $4 \%$ and more on the day of publication. Large positive returns are chosen because insiders might not be able to use their information on negative information as easily because of short selling restrictions or other constraints (e.g. a minimum holding period of the company's stocks). The results are not critically dependent on the $4 \%$ cut-off level.

\section{Data}

The news data used in this study is provided by Hugin.[7] Hugin is an international service that collects and publishes press releases of companies who choose to use Hugin as a platform for distributing their publications.

The time frame covered in this study ranges from January $1^{\text {st }}, 1997$ to July $24^{\text {th }}, 2003$. The beginning of the time frame is determined by the quality and quantity of information available via Hugin. After January 1997, the number of press releases available from the data provider increases rapidly. Therefore, starting before 1997 did not seem advisable because of the low quantity of reliable input data. By choosing the given time interval, this study captures the strong rise in stock market prices at the end of the 90s but also the strong decline of stock markets at the beginning of the new millenium. Therefore the time frame covered seems balanced with respect to up- and down-markets.

From all the companies listed on Hugin's internet homepage we use only those that confirmed upon request by email the use of Hugin for the publication of press releases or whose homepage contained information to that effect. In total, 42 companies are included in the sample. They are listed in the appendix (Tables A1 and A2). The companies are very heterogeneous, covering a broad range regarding size, market capitalization and area of business. For all of these companies, the press releases available on www.huginonline.ch are evaluated. 
The total sample of 42 firms is separated into subsamples according to two different criteria. Table A1 shows the subsamples generated by a marketvalue (MV) criterion. Table A2 shows the subsamples generated by a market-to-book-value (MTBV) criterion.

The study is separated into two different types of news releases: The release of financial accounting statements and the release of corporate control actions. The press releases with financial accounting information are categorized after the publication of a complete report, a preliminary report and sales announcements, each one for annual, halfyear and quarterly reports. If there are special information releases regarding accounting items of a company, they are grouped into an extra class. Thus, there is a total of 13 different categories for the release of financial accounting information. The press releases with announcements of corporate control actions are classified into the announcement of a take-over bid, a completed acquisition or a sale of a business unit. The news relate to a corporate control action done by a company in the sample. None of the corporate control actions includes an acquisition of one of the companies in the sample by another company, which would be the typical way to study takeover effects.[8] Therefore, no takeover effect is analyzed. In total, 742 events are included into the sample, 536 of which are related to new accounting information and 206 events are related to corporate control actions. Some of the companies in the sample do not use Hugin for the whole time period covered by this study. This is not likely to induce a bias since there is no systematic pattern to this.

The Swiss Market Index (SMI) is chosen as the market index of the market model. The results of the regression turn out to be relatively insensitive to the choice of the market index. The stock price data and the turnover figures used in this study are from Datastream.

\section{Empirical Results \\ 6.1 Financial Statements}

In this chapter the results for the releases of financial statements are discussed. The base case with a pre- and post-event window of 10 days and an information processing period (IPP) of 5 days with the complete dataset is summarized in Table 1. The base case shows a significantly positive return for the pre-event window (PEW). Looking at the daily returns, this seems to be driven by a highly significant positive return on the $3^{\text {rd }}$ day in the PEW (3.41 standard deviations). Separated into positive and negative events, the score drops below significance, but is still at 1.42 and -1.49 standard deviations, respectively. Since the returns are corrected for systematic changes, the abnormal returns are interpreted to be caused by new information reaching the market, perhaps even by insider trading. Detrending does not change these results.

The volume is not significantly above average in the PEW. In fact, it is even decreasing significantly for the total sample and the positive events whereas it is increasing before negative events. It is interesting that the returns take the right direction for insider trading, but that the volume reacts ambiguously. However, for bad news there are close-to-significant negative returns and an increase in volume. Hence there is selling pressure on the stock resulting in increased volume, giving weak evidence for systematic insider trading on bad news. Obviously, the way information is processed depends on the content of the news. The drop in volume for positive news might be brought about by market participants waiting for the new information to arrive on the announced release dates. Although this is no evidence for insider activities, it is no evidence against it either, since the drop in volume caused by the waiting of uninformed investors might be much larger than the additional volume (possibly) caused by insiders, resulting in a decreasing overall trade volume. The abnormal returns on day three are not supported by abnormally high 
Table 1: Financial Statements - Results for the Base Case

\begin{tabular}{|c|c|c|c|c|c|c|c|c|}
\hline $\begin{array}{l}\text { Eventtype } \\
\text { Frequency }\end{array}$ & $\begin{array}{c}\text { All Events } \\
536 \\
\end{array}$ & $\begin{array}{c}\text { Annual } \\
156\end{array}$ & $\begin{array}{l}\text { Q3 } \\
72 \\
\end{array}$ & $\begin{array}{r}Q 2 \\
131 \\
\end{array}$ & $\begin{array}{l}\text { Q1 } \\
74\end{array}$ & $\begin{array}{c}\text { Ann. + Q2 } \\
287\end{array}$ & $\begin{array}{c}\text { Q3 + Q1 } \\
146\end{array}$ & $\begin{array}{c}\text { Special } \\
7 \\
\end{array}$ \\
\hline \multicolumn{9}{|l|}{ Results of Returns } \\
\hline \multicolumn{9}{|l|}{ Test Statistics } \\
\hline Returns $\left(\theta_{1}\right)$ & 2.0558 & 1.4217 & 1.5977 & 0.3015 & 0.1950 & 1.1801 & 1.3039 & 0.2804 \\
\hline Returns Positive $\left(\theta_{1}\right)$ & 1.4217 & 1.1755 & 1.4155 & -0.0776 & 0.4192 & 0.7345 & 1.2428 & 0.2358 \\
\hline Returns Negative $\left(\theta_{1}\right)$ & -1.4921 & -0.8141 & -0.8935 & -0.5502 & 0.2439 & -0.9547 & -0.5837 & -0.1588 \\
\hline Ret. Before/After $\left(\theta_{3}\right)$ & -0.0745 & -0.2959 & 1.1532 & -0.5424 & -0.1251 & -0.6041 & 0.7036 & 1.6473 \\
\hline \multicolumn{9}{|c|}{ Daywise Abnormal Returns } \\
\hline 1 & 0.0018 & $0.0041^{* *}$ & 0.0052 & 0.0011 & -0.0022 & 0.0027 & 0.0015 & 0.0060 \\
\hline 2 & 0.0013 & -0.0001 & 0.0004 & -0.0008 & 0.0016 & -0.0004 & 0.0010 & 0.0110 \\
\hline 3 & $0.0043^{* *}$ & $0.0045^{\star *}$ & 0.0058 & $0.0046^{*}$ & -0.0033 & $0.0045^{\star *}$ & 0.0012 & 0.0009 \\
\hline 4 & 0.0002 & -0.0017 & -0.0014 & 0.0005 & $0.0073^{* *}$ & -0.0007 & 0.0030 & -0.0110 \\
\hline 5 & -0.0004 & 0.0028 & -0.0002 & -0.0019 & -0.0026 & 0.0006 & -0.0014 & -0.0089 \\
\hline 6 & 0.0018 & -0.0009 & $0.0078^{* *}$ & 0.0007 & $0.0060^{*}$ & -0.0001 & $0.0069^{* *}$ & -0.0008 \\
\hline 7 & -0.0015 & $-0.0039^{\star}$ & -0.0035 & 0.0008 & -0.0019 & -0.0017 & -0.0027 & 0.0011 \\
\hline 8 & -0.0001 & 0.0004 & 0.0033 & -0.0004 & 0.0006 & 0.0000 & 0.0020 & -0.0016 \\
\hline 9 & 0.0005 & 0.0022 & 0.0006 & -0.0006 & -0.0012 & 0.0009 & -0.0003 & 0.0046 \\
\hline 10 & 0.0003 & 0.0020 & 0.0017 & -0.0014 & -0.0022 & 0.0004 & -0.0003 & 0.0123 \\
\hline 11 & $0.0246^{* *}$ & $0.0217^{* *}$ & $0.0202^{* *}$ & $0.0293^{\star *}$ & $0.0161^{* *}$ & $0.0252^{* *}$ & $0.0181^{* *}$ & 0.1639 ** \\
\hline 12 & $0.0129^{* *}$ & $0.0114^{* *}$ & $0.0186^{* *}$ & $0.0128^{* *}$ & $0.0137^{* *}$ & $0.0121^{* *}$ & $0.0161^{* *}$ & 0.0161 \\
\hline 13 & $0.0096^{* *}$ & $0.0104^{* *}$ & $0.0094^{* *}$ & $0.0121^{* *}$ & 0.0042 & $0.0112^{\star *}$ & $0.0068^{* *}$ & 0.0318 ** \\
\hline 14 & $0.0044^{* *}$ & 0.0034 & 0.0024 & $0.0059^{* *}$ & $0.0060^{*}$ & $0.0045^{\star *}$ & 0.0042 & -0.0069 \\
\hline 15 & $0.0042^{* *}$ & $0.0051^{* *}$ & 0.0062 & 0.0016 & $0.0085^{\star \star}$ & $0.0035^{\star *}$ & $0.0074^{* *}$ & -0.0019 \\
\hline 16 & 0.0014 & 0.0009 & 0.0008 & 0.0031 & 0.0057 & 0.0019 & 0.0033 & $-0.0432^{* *}$ \\
\hline 17 & -0.0006 & -0.0012 & -0.0001 & 0.0020 & -0.0027 & 0.0002 & -0.0014 & -0.0087 \\
\hline 18 & 0.0016 & 0.0014 & 0.0001 & 0.0021 & -0.0024 & 0.0017 & -0.0011 & 0.0018 \\
\hline 19 & -0.0012 & 0.0015 & -0.0053 & -0.0032 & 0.0000 & -0.0006 & -0.0026 & -0.0061 \\
\hline 20 & 0.0005 & 0.0016 & 0.0005 & 0.0002 & 0.0009 & 0.0010 & 0.0007 & -0.0183 \\
\hline 21 & -0.0007 & 0.0004 & -0.0002 & -0.0018 & -0.0013 & -0.0006 & -0.0007 & -0.0087 \\
\hline \multicolumn{9}{|c|}{ Cumulated Abnormal Returns } \\
\hline 1 & 0.0018 & 0.0041 & 0.0052 & 0.0011 & -0.0022 & 0.0027 & 0.0015 & 0.0060 \\
\hline 2 & 0.0031 & 0.0040 & 0.0056 & 0.0003 & -0.0006 & 0.0023 & 0.0025 & 0.0170 \\
\hline 3 & 0.0073 & 0.0085 & 0.0114 & 0.0049 & -0.0039 & 0.0069 & 0.0037 & 0.0179 \\
\hline 4 & 0.0076 & 0.0068 & 0.0101 & 0.0054 & 0.0034 & 0.0062 & 0.0067 & 0.0069 \\
\hline 5 & 0.0071 & 0.0096 & 0.0098 & 0.0035 & 0.0008 & 0.0068 & 0.0053 & -0.0020 \\
\hline 6 & 0.0090 & 0.0087 & 0.0176 & 0.0043 & 0.0068 & 0.0067 & 0.0122 & -0.0028 \\
\hline 7 & 0.0075 & 0.0048 & 0.0142 & 0.0051 & 0.0049 & 0.0049 & 0.0095 & -0.0016 \\
\hline 8 & 0.0074 & 0.0052 & 0.0175 & 0.0047 & 0.0056 & 0.0049 & 0.0114 & -0.0032 \\
\hline 9 & 0.0078 & 0.0074 & 0.0181 & 0.0040 & 0.0044 & 0.0058 & 0.0112 & 0.0014 \\
\hline 10 & 0.0081 & 0.0094 & 0.0198 & 0.0026 & 0.0022 & 0.0063 & 0.0109 & 0.0137 \\
\hline 11 & 0.0327 & 0.0311 & 0.0401 & 0.0319 & 0.0183 & 0.0314 & 0.0290 & 0.1775 \\
\hline 12 & 0.0456 & 0.0425 & 0.0586 & 0.0447 & 0.0319 & 0.0435 & 0.0451 & 0.1937 \\
\hline 13 & 0.0552 & 0.0530 & 0.0681 & 0.0568 & 0.0361 & 0.0547 & 0.0519 & 0.2255 \\
\hline 14 & 0.0596 & 0.0563 & 0.0705 & 0.0627 & 0.0421 & 0.0593 & 0.0561 & 0.2186 \\
\hline 15 & 0.0638 & 0.0614 & 0.0767 & 0.0643 & 0.0506 & 0.0627 & 0.0635 & 0.2167 \\
\hline 16 & 0.0652 & 0.0623 & 0.0775 & 0.0674 & 0.0564 & 0.0646 & 0.0668 & 0.1735 \\
\hline 17 & 0.0646 & 0.0611 & 0.0774 & 0.0694 & 0.0537 & 0.0649 & 0.0654 & 0.1648 \\
\hline 18 & 0.0662 & 0.0625 & 0.0776 & 0.0715 & 0.0513 & 0.0666 & 0.0643 & 0.1666 \\
\hline 19 & 0.0650 & 0.0640 & 0.0723 & 0.0683 & 0.0513 & 0.0660 & 0.0617 & 0.1605 \\
\hline 20 & 0.0655 & 0.0656 & 0.0728 & 0.0685 & 0.0522 & 0.0669 & 0.0624 & 0.1421 \\
\hline 21 & 0.0647 & 0.0661 & 0.0726 & 0.0667 & 0.0510 & 0.0664 & 0.0616 & 0.1334 \\
\hline
\end{tabular}


Table 1: Financial Statements - Results for the Base Case (cont.)

\begin{tabular}{|c|c|c|c|c|c|c|c|c|}
\hline $\begin{array}{l}\text { Eventtype } \\
\text { Frequency }\end{array}$ & $\begin{array}{l}\text { All Events } \\
536\end{array}$ & $\begin{array}{c}\text { Annual } \\
156\end{array}$ & $\begin{array}{l}\text { Q3 } \\
72\end{array}$ & $\begin{array}{c}\text { Q2 } \\
131\end{array}$ & $\begin{array}{l}\text { Q1 } \\
74\end{array}$ & $\begin{array}{c}\text { Ann. + Q2 } \\
287\end{array}$ & $\begin{array}{c}3+Q 1 \\
146\end{array}$ & $\begin{array}{c}\text { Special } \\
7 \\
\end{array}$ \\
\hline \multicolumn{9}{|l|}{ Results for the Volume } \\
\hline $\begin{array}{l}\text { Non-parametric Test }\left(\theta_{5}\right) \\
\text { T-test }\left(\theta_{4}\right) \\
\text { Non-par. Test Positive }\left(\theta_{5}\right) \\
\text { T-test Positive }\left(\theta_{4}\right) \\
\text { Non-par. Test Negative }\left(\theta_{5}\right) \\
\text { T-test Negative }\left(\theta_{4}\right)\end{array}$ & $\begin{array}{r}-1.9396 \\
0.1045 \\
-3.3180 \\
-1.8979 \\
0.6264 \\
2.2297 \\
\end{array}$ & $\begin{array}{l}-3.4433 \\
-1.3153 \\
-3.0007 \\
-0.0019 \\
-1.7671 \\
-1.9565 \\
\end{array}$ & $\begin{array}{r}-0.8199 \\
-1.8888 \\
0.0000 \\
-2.5016 \\
-1.0865 \\
-0.0850 \\
\end{array}$ & $\begin{array}{r}0.4421 \\
1.9693 \\
-2.0080 \\
0.2191 \\
2.5126 \\
2.3178 \\
\end{array}$ & $\begin{array}{l}-2.3527 \\
-4.1001 \\
-1.0865 \\
-3.3018 \\
-2.3120 \\
-2.4519 \\
\end{array}$ & $\begin{array}{r}-2.2400 \\
0.2880 \\
-3.5952 \\
0.1252 \\
0.6078 \\
0.2783 \\
\end{array}$ & $\begin{array}{l}-2.2507 \\
-4.2333 \\
-0.8199 \\
-4.1336 \\
-2.3527 \\
-1.5738 \\
\end{array}$ & $\begin{array}{r}0.7171 \\
1.7391 \\
-0.8944 \\
0.2857 \\
1.4142 \\
1.7389 \\
\end{array}$ \\
\hline \multicolumn{9}{|c|}{ Hypothesis Test of Daywise Volume $\left(\theta_{6}\right)$} \\
\hline 1 & -0.9503 & -2.4019 & 0.4714 & -0.2621 & 0.0000 & -1.9479 & 0.3310 & -0.3780 \\
\hline 2 & -1.3822 & -2.5621 & -0.2357 & -0.4369 & 0.0000 & -2.1840 & -0.1655 & -0.3780 \\
\hline 3 & -1.9005 & -1.9215 & -1.1785 & -1.3106 & -1.1625 & -2.3021 & -1.6552 & 0.3780 \\
\hline 4 & -1.1230 & -1.7614 & -0.7071 & -0.6116 & 0.2325 & -1.7118 & -0.3310 & 1.1339 \\
\hline 5 & -1.5550 & -2.4019 & -0.7071 & 0.0874 & -1.1625 & -1.7118 & -1.3242 & 1.1339 \\
\hline 6 & -0.1728 & 0.4804 & 1.6499 & -0.7863 & -1.6275 & -0.1771 & 0.0000 & 0.3780 \\
\hline 7 & -1.4686 & -1.4412 & -1.1785 & 0.0874 & -0.6975 & -1.0035 & -1.3242 & -0.3780 \\
\hline 8 & 0.2592 & 0.3203 & -0.7071 & 0.4369 & 0.2325 & 0.5313 & -0.3310 & 0.3780 \\
\hline 9 & 1.2958 & 0.4804 & 0.0000 & 2.3590 & -2.0925 & 1.9479 & -1.4897 & -0.3780 \\
\hline 10 & 0.8639 & 0.3203 & 0.0000 & 1.8348 & -1.1625 & 1.4757 & -0.8276 & 0.3780 \\
\hline 11 & 13.2172 & 7.2058 & 4.7140 & 6.9023 & 4.8824 & 9.9758 & 6.7864 & 1.8898 \\
\hline 12 & 9.3298 & 5.7646 & 3.0641 & 4.8054 & 2.5574 & 7.4966 & 3.9725 & -0.3780 \\
\hline 13 & 5.2696 & 3.3627 & 1.1785 & 2.7085 & 0.9300 & 4.3091 & 1.4897 & 0.3780 \\
\hline 14 & 5.4424 & 3.0424 & 0.7071 & 4.4559 & -0.2325 & 5.2535 & 0.3310 & -0.3780 \\
\hline 15 & 2.0733 & 1.6013 & -0.2357 & 1.3106 & -0.4650 & 2.0660 & -0.4966 & -0.3780 \\
\hline 16 & 2.9372 & 3.2026 & 1.4142 & 0.6116 & -0.6975 & 2.7743 & 0.4966 & 0.3780 \\
\hline 17 & 1.5550 & 1.7614 & 0.4714 & -0.0874 & -0.9300 & 1.2396 & -0.3310 & -0.3780 \\
\hline 18 & 0.0000 & 1.9215 & -1.1785 & 0.6116 & -1.8600 & 1.8299 & -2.1518 & -1.1339 \\
\hline 19 & 0.2592 & 0.1601 & 0.4714 & 0.6116 & -1.3950 & 0.5313 & -0.6621 & -1.1339 \\
\hline 20 & 0.9503 & 0.8006 & 0.2357 & 0.6116 & -2.0925 & 1.0035 & -1.3242 & 1.1339 \\
\hline 21 & -0.1728 & 1.4412 & 0.7071 & -1.8348 & -1.3950 & -0.1771 & -0.4966 & -0.3780 \\
\hline
\end{tabular}

The table shows in the columns the results for the different event types of the base case. In the first section the results of the t-tests on the abnormal returns are reported, whereas positive stands for the positive events subsample and negative for the negative events subsample. In the second part the daily abnormal returns are shown. ${ }^{*}$ : Significance level of $5 \%$, *: Significance level of $10 \%$. The gray line emphasizes the day of the information release. The third section contains the cumulated abnormal returns, starting on day one. In the fourth section the results for the tests on abnormal volume are shown. The last section contains the results for the non-parametric tests on daily abnormal volume.

volumes. Results for the base case are stable using IPPs of different length (results not shown here).

The abnormal returns last for at least three days (depending on the chosen IPP) including the announcement day. On the event day itself there is an abnormal return of $2.46 \%$. This figure decreases fast in the following days. Significant abnormal returns could be earned by buying or selling stocks immediately after an information event and keeping the position for three days. This is evidence against the semi-strong form of efficiency on the Swiss market. Additionally, there are significant deviations from the median trading volume for six days, emphasizing the findings for the returns and indicating that information processing at the market takes several days. With the volume statistic being independent of the IPP, this result reduces 
concerns regarding a selection bias connected with the identification of the news content.

Introducing a hurdle rate of $4 \%$ delivers mixed results that are not reported here. Although the incentive for events with a large price impact is stronger, no significant abnormal returns are de- tected in the PEW. The volume in the PEW drops for all news contents. The non-parametric tests show a significant drop. The liquidity dry-out is more pronounced than before. Again, the capital markets seem to be in a waiting position before important information releases. After the release

Table 2: Financial Statements - Low Market Values

\begin{tabular}{|c|c|c|c|c|c|c|c|c|}
\hline $\begin{array}{l}\text { Eventtype } \\
\text { Frequency }\end{array}$ & $\begin{array}{c}\text { All Events } \\
257 \\
\end{array}$ & $\begin{array}{c}\text { Annual } \\
75 \\
\end{array}$ & $\begin{array}{l}\text { Q3 } \\
36 \\
\end{array}$ & $\begin{array}{l}\text { Q2 } \\
68 \\
\end{array}$ & $\begin{array}{l}\text { Q1 } \\
30 \\
\end{array}$ & $\begin{array}{c}\text { Ann. + Q2 } \\
143 \\
\end{array}$ & $\begin{array}{c}Q 3+Q 1 \\
66 \\
\end{array}$ & $\begin{array}{c}\text { Special } \\
3 \\
\end{array}$ \\
\hline \multicolumn{9}{|l|}{ Results for the Returns } \\
\hline \multicolumn{9}{|l|}{ Test Statistics } \\
\hline Returns $\left(\theta_{1}\right)$ & 1.3093 & 1.0855 & 1.0965 & -0.2640 & -0.2070 & 0.5992 & 0.6596 & 0.3882 \\
\hline Returns Positive $\left(\theta_{1}\right)$ & 0.3711 & 0.2703 & 0.4718 & -0.1204 & -0.0586 & 0.1210 & 0.2490 & 0.2358 \\
\hline Returns Negative $\left(\theta_{1}\right)$ & -1.4962 & -1.3127 & -1.0196 & 0.2495 & 0.2732 & -0.7323 & -0.6858 & -0.3781 \\
\hline Ret. Before/After $\left(\theta_{3}\right)$ & -0.5573 & -0.3584 & 0.8164 & -0.8977 & -0.6694 & -0.9016 & 0.1341 & 1.2447 \\
\hline \multicolumn{9}{|c|}{ Daywise Abnormal Returns } \\
\hline 1 & 0.0021 & $0.0076^{\star *}$ & 0.0058 & -0.0017 & -0.0038 & 0.0032 & 0.0014 & 0.0059 \\
\hline 2 & 0.0023 & 0.0010 & -0.0016 & -0.0013 & 0.0053 & -0.0001 & 0.0015 & 0.0332 \\
\hline 3 & $0.0078^{* *}$ & $0.0093^{\star *}$ & 0.0099 & $0.0098^{\star *}$ & -0.0088 & $0.0095^{\star \star}$ & 0.0014 & -0.0059 \\
\hline 4 & -0.0006 & -0.0052 & 0.0014 & -0.0011 & $0.0143^{*}$ & -0.0033 & 0.0073 & -0.0287 \\
\hline 5 & -0.0018 & 0.0026 & -0.0029 & -0.0024 & -0.0047 & 0.0002 & -0.0037 & -0.0086 \\
\hline 6 & 0.0030 & 0.0006 & $0.0122^{*}$ & 0.0000 & 0.0097 & 0.0003 & $0.0111^{* *}$ & -0.0215 \\
\hline 7 & $-0.0040^{*}$ & $-0.0094^{* *}$ & -0.0043 & 0.0014 & -0.0110 & -0.0042 & -0.0074 & 0.0220 \\
\hline 8 & -0.0005 & 0.0012 & 0.0003 & -0.0015 & 0.0008 & -0.0001 & 0.0006 & -0.0034 \\
\hline 9 & 0.0019 & 0.0041 & 0.0010 & -0.0013 & -0.0033 & 0.0015 & -0.0009 & 0.0480 \\
\hline 10 & -0.0011 & 0.0013 & 0.0015 & -0.0053 & -0.0033 & -0.0018 & -0.0007 & -0.0045 \\
\hline 11 & $0.0256^{* *}$ & $0.0205^{\star *}$ & $0.0281^{* *}$ & $0.0288^{* *}$ & $0.0198^{* *}$ & $0.0244^{* *}$ & $0.0243^{* *}$ & 0.0463 \\
\hline 12 & $0.0180^{* *}$ & $0.0181^{\star *}$ & $0.0199^{\star *}$ & $0.0185^{\star *}$ & $0.0200^{* *}$ & $0.0183^{* *}$ & $0.0200^{* *}$ & 0.0054 \\
\hline 13 & $0.0119^{* *}$ & $0.0146^{* *}$ & $0.0116^{*}$ & $0.0128^{* *}$ & 0.0051 & $0.0137^{* *}$ & $0.0086^{*}$ & 0.0238 \\
\hline 14 & $0.0038^{*}$ & 0.0031 & 0.0005 & $0.0068^{*}$ & 0.0043 & $0.0049^{*}$ & 0.0023 & -0.0415 \\
\hline 15 & $0.0053^{* *}$ & 0.0060 & 0.0085 & 0.0026 & $0.0144^{*}$ & 0.0044 & $0.0112^{* *}$ & 0.0398 \\
\hline 16 & 0.0034 & 0.0003 & 0.0018 & $0.0084^{* *}$ & 0.0111 & 0.0042 & 0.0060 & -0.0483 \\
\hline 17 & -0.0002 & 0.0009 & -0.0008 & -0.0022 & -0.0003 & -0.0006 & -0.0006 & -0.0064 \\
\hline 18 & 0.0030 & -0.0006 & 0.0046 & 0.0029 & -0.0021 & 0.0011 & 0.0016 & -0.0002 \\
\hline 19 & -0.0026 & 0.0011 & -0.0053 & -0.0043 & -0.0020 & -0.0015 & -0.0038 & -0.0107 \\
\hline 20 & 0.0001 & 0.0026 & -0.0041 & 0.0005 & 0.0029 & 0.0016 & -0.0009 & -0.0283 \\
\hline 21 & -0.0020 & 0.0007 & -0.0052 & -0.0010 & -0.0057 & -0.0001 & -0.0054 & -0.0014 \\
\hline
\end{tabular}

\section{Results for the Volume}

\begin{tabular}{lrrrrrrrr}
\hline Non-parametric Test $\left(\theta_{5}\right)$ & -3.7084 & -1.8988 & -1.2649 & -0.9971 & -1.6166 & -2.0627 & -2.0241 & -1.4606 \\
T-test $\left(\theta_{4}\right)$ & 7.1618 & 5.9816 & 0.5392 & 5.6287 & 1.0637 & 7.9681 & 1.1903 & -0.3263 \\
Non-par. Test Positive $\left(\theta_{5}\right)$ & -2.4866 & -0.3904 & -0.3381 & -2.8625 & 0.3068 & -2.1909 & 0.0000 & -0.8944 \\
T-test Positive $\left(\theta_{4}\right)$ & 7.2021 & 7.9402 & -0.4066 & 0.6922 & -0.4439 & 7.4314 & -0.6015 & 0.2857 \\
Non-par. Test Negative $\left(\theta_{5}\right)$ & -2.7608 & -2.4221 & -1.3484 & 1.3898 & -2.8066 & -0.6903 & -2.7795 & -1.2649 \\
T-test Negative $\left(\theta_{4}\right)$ & 3.3245 & -2.0777 & 1.0737 & 8.0140 & 1.2424 & 3.1158 & 1.5213 & -0.9550 \\
\hline
\end{tabular}

The table shows in the columns the results for the different event types of the low market value case. In the first section the results of the t-tests on the abnormal returns are reported, whereas positive stands for the positive events subsample and negative for the negative events subsample. In the second part the daily abnormal returns are shown. ${ }^{\star *}$ : Significance level of $5 \%$, *: Significance level of $10 \%$. The gray line emphasizes the day of the information release. The last section shows the results for the tests on abnormal volume. 
of the information, the abnormal returns and daily volumes turn much faster into noise than in the base case. The information processing is thus faster when important information is released. This could be caused by the larger media attention towards news with a large price impact, resulting in a faster processing of the information. This effect could also be caused by the lower statistical power of the tests in the smaller subsample of events above the hurdle rate.

Another point worth mentioning is the significance of $\theta_{3}$, indicating a drift upon information processing.[9] Whereas there is just noise in returns starting 5 days after the release in the base case, there is a $1.81 \%$ average cumulative abnormal return for the hurdle-rate case for days 16 to 21 . Although the information is processed faster, the price continues to move in the direction of the announcement effect, possibly because of a more thorough analysis of the new information. This comparison to the base case is not biased by the classification procedure of the news content, since the events with a heavy price reaction of $4 \%$ are predominantly positive events and quite insensitive to the chosen IPP.

It could be conjectured, as in SEYHUN (1986), that there is more insider trading in smaller com- panies because smaller companies have, perhaps, less developed corporate governance guidelines. Additionally, small companies do not have as much media attention as large companies. This could lead to slower information processing. The size of a company is measured by market value (MV). To test those hypotheses, the dataset is split in high and low MV companies with a total of 279 and 257 events, respectively. Results are reported in Tables 2 and 3. For low MV companies there are no significant abnormal returns in the PEW as a total (Table 2) but the $3^{\text {rd }}$ day in the PEW remains significant, though without a significant increase in daily volume. The speed of information processing is not faster than in the base case. The period of abnormal returns after the event stays unchanged. There are no drifts after the announcement as observed for the $4 \%$ hurdle rate. Furthermore, for both groups, the announcement day effects are similar, whereas in the four days afterwards the cumulated abnormal returns for low MV companies are larger. Everything else equal, low MV companies show stronger reactions to financial information, which is illustrated by Figure 2. For companies with large MV, there is no significant day in the PEW (Table 3), but the

Figure 2: Cumulated Returns for Financial Statement Events - Low vs. High MV

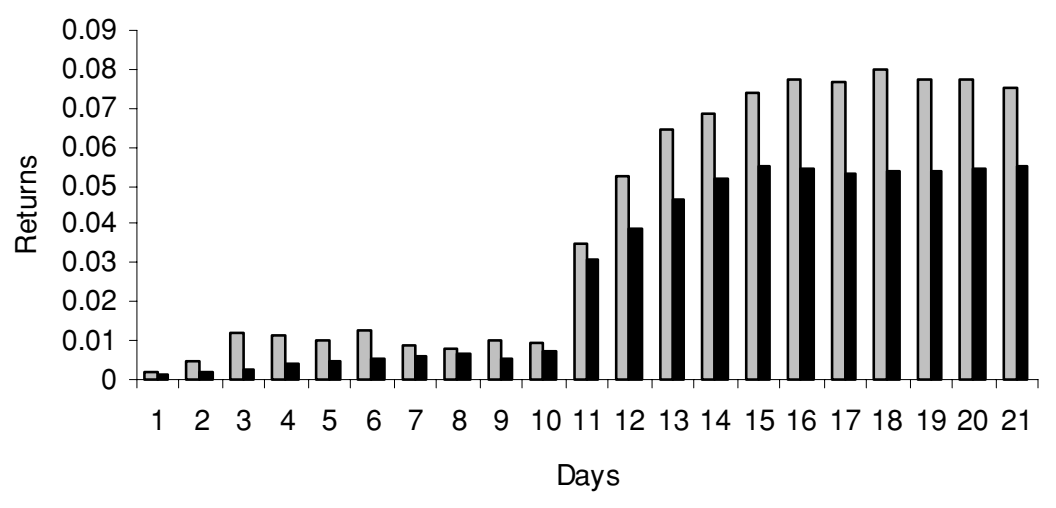

$\square$ Low MV $\square$ High MV 
overall window exhibits significant abnormal returns at the $10 \%$ level, suggesting that there is systematic trading before the release of financial information. Considering positive events only, abnormal returns are close to significance at the $5 \%$ level.
The volume statistics show an interesting pattern for low MV companies. The non-parametric tests all indicate a significant drop of volume in the PEW, whereas the t-statistics indicate a significant increase in volume. The solution to this puzzle is found in the way the statistics are constructed. For

Table 3: Financial Statements - High Market Values

\begin{tabular}{|c|c|c|c|c|c|c|c|c|}
\hline $\begin{array}{l}\text { Eventtype } \\
\text { Frequency }\end{array}$ & $\begin{array}{c}\text { All Events } \\
279 \\
\end{array}$ & $\begin{array}{c}\text { Annual } \\
81\end{array}$ & $\begin{array}{l}\text { Q3 } \\
36\end{array}$ & $\begin{array}{l}\text { Q2 } \\
63\end{array}$ & $\begin{array}{l}\text { Q1 } \\
44\end{array}$ & $\begin{array}{c}\text { Ann. + Q2 } \\
144 \\
\end{array}$ & $\begin{array}{c}\mathrm{Q3}+\mathrm{Q1} \\
80\end{array}$ & $\begin{array}{c}\text { Special } \\
4\end{array}$ \\
\hline \multicolumn{9}{|l|}{ Results for the Returns } \\
\hline \multicolumn{9}{|l|}{ Test Statistics } \\
\hline Returns $\left(\theta_{1}\right)$ & 1.7643 & 0.9847 & 1.2789 & 0.7954 & 0.7448 & 1.2105 & 1.4477 & -0.0722 \\
\hline Returns Positive $\left(\theta_{1}\right)$ & 1.9328 & 1.8454 & 1.7442 & 0.0097 & 0.9514 & 1.0180 & 1.9165 & NA \\
\hline Returns Negative $\left(\theta_{1}\right)$ & -0.3849 & 0.9201 & 0.0417 & -1.4835 & 0.0194 & -0.6549 & 0.0445 & 0.0722 \\
\hline Ret. Before/After $\left(\theta_{3}\right)$ & 0.7012 & 0.0310 & 0.8831 & 0.3032 & 0.6139 & 0.2643 & 1.0238 & 1.0867 \\
\hline \multicolumn{9}{|l|}{ Daywise Abnormal Returns } \\
\hline 1 & 0.0014 & 0.0009 & 0.0047 & 0.0041 & -0.0011 & 0.0023 & 0.0015 & 0.0061 \\
\hline 2 & 0.0004 & -0.0011 & 0.0024 & -0.0002 & -0.0009 & -0.0007 & 0.0006 & -0.0056 \\
\hline 3 & 0.0010 & 0.0000 & 0.0018 & -0.0009 & 0.0005 & -0.0004 & 0.0011 & 0.0060 \\
\hline 4 & 0.0010 & 0.0016 & -0.0041 & 0.0022 & 0.0025 & 0.0019 & -0.0005 & 0.0023 \\
\hline 5 & 0.0009 & 0.0030 & 0.0024 & -0.0014 & -0.0011 & 0.0010 & 0.0005 & -0.0091 \\
\hline 6 & 0.0007 & -0.0023 & 0.0034 & 0.0016 & 0.0035 & -0.0006 & 0.0034 & 0.0148 \\
\hline 7 & 0.0008 & 0.0012 & -0.0027 & 0.0001 & 0.0043 & 0.0007 & 0.0012 & -0.0145 \\
\hline 8 & 0.0003 & -0.0004 & 0.0063 & 0.0008 & 0.0005 & 0.0002 & 0.0031 & -0.0003 \\
\hline 9 & -0.0008 & 0.0004 & 0.0003 & 0.0001 & 0.0003 & 0.0003 & 0.0003 & $-0.0279^{*}$ \\
\hline 10 & 0.0016 & 0.0027 & 0.0019 & 0.0027 & -0.0014 & 0.0027 & 0.0001 & 0.0248 \\
\hline 11 & $0.0237^{* *}$ & $0.0229^{* *}$ & $0.0124^{* *}$ & $0.0298^{* *}$ & $0.0136^{* *}$ & * $0.0259^{* *}$ & 0.0130 ** & $0.2521^{* *}$ \\
\hline 12 & $0.0083^{* *}$ & $0.0053^{* *}$ & $0.0172^{* *}$ & $0.0067^{\star}$ & $0.0093^{* *}$ & * 0.0059 ** & $0.0129^{* *}$ & 0.0242 \\
\hline 13 & $0.0074^{* *}$ & $0.0067^{* *}$ & $0.0073^{*}$ & $0.0113^{* *}$ & 0.0036 & $0.0087^{* *}$ & $0.0052^{* *}$ & $0.0378^{* *}$ \\
\hline 14 & $0.0049^{* *}$ & $0.0036^{*}$ & 0.0043 & 0.0050 & $0.0072^{* *}$ & * $0.0042^{* *}$ & $0.0059^{* *}$ & 0.0191 \\
\hline 15 & $0.0032^{* *}$ & $0.0042^{* *}$ & 0.0039 & 0.0004 & 0.0045 & 0.0026 & $0.0042^{*}$ & $-0.0331^{* *}$ \\
\hline 16 & -0.0005 & 0.0015 & -0.0002 & -0.0026 & 0.0021 & -0.0003 & 0.0010 & $-0.0394^{* *}$ \\
\hline 17 & -0.0010 & $-0.0032^{*}$ & 0.0006 & $0.0065^{*}$ & -0.0043 & 0.0010 & -0.0021 & -0.0104 \\
\hline 18 & 0.0003 & $0.0033^{*}$ & -0.0044 & 0.0012 & -0.0025 & 0.0024 & -0.0034 & 0.0033 \\
\hline 19 & 0.0001 & 0.0019 & -0.0052 & -0.0020 & 0.0014 & 0.0002 & -0.0016 & -0.0027 \\
\hline 20 & 0.0009 & 0.0008 & 0.0051 & -0.0001 & -0.0004 & 0.0004 & 0.0021 & -0.0108 \\
\hline 21 & 0.0004 & 0.0002 & 0.0048 & -0.0027 & 0.0018 & -0.0011 & 0.0032 & -0.0142 \\
\hline \multicolumn{9}{|l|}{ Results for the Volume } \\
\hline Non-parametric Test $\left(\theta_{5}\right)$ & 0.8709 & -2.9515 & 0.1054 & 1.6733 & -1.7162 & -1.1068 & -1.2021 & 2.2136 \\
\hline T-test $\left(\theta_{4}\right)$ & 0.0233 & -1.3952 & -1.8918 & 1.9206 & -4.1141 & 0.1958 & -4.2452 & 1.7393 \\
\hline Non-par. Test Positive $\left(\theta_{5}\right)$ & -2.2136 & -3.6836 & 0.3068 & 0.1174 & -1.6783 & -2.8812 & -1.0865 & NA \\
\hline T-test Positive $\left(\theta_{4}\right)$ & -1.9688 & -0.1275 & -2.4996 & 0.2115 & -3.2999 & 0.0184 & -4.1309 & NA \\
\hline Non-par. Test Negative $\left(\theta_{5}\right)$ & ) 3.5382 & 0.0000 & -0.1451 & 2.1693 & -0.7071 & 1.5936 & -0.6076 & 2.2136 \\
\hline T-test Negative $\left(\theta_{4}\right)$ & 2.1869 & -1.9369 & -0.0915 & 2.2621 & -2.4812 & 0.2524 & -1.5968 & 1.7393 \\
\hline
\end{tabular}

The table shows in the columns the results for the different event types of the high market value case. In the first section the results of the t-tests on the abnormal returns are reported, whereas positive stands for the positive events subsample and negative for the negative events subsample. In the second part the daily abnormal returns are shown. ${ }^{* *}$ : Significance level of $5 \%$, *: Significance level of $10 \%$. The gray line emphasizes the day of the information release. The last section shows the results for the tests on abnormal volume. 
the majority of the events, the volume in the PEW is below the median during the estimation period, but for the events where the volume does increase, it seems to increases so much that it overcompensates the volume decrease resulting from other events. Looking at the volume of high MV companies in the PEW, the volume decreases for good news and increases significantly for bad news. This is in line with the base case as well. After the event there are abnormally high volumes until day 16. Although the results for the daily abnormal volumes are less clear for low MV companies than for high MV companies or the base case, the differences are small. Thus, for the hypothesis regarding the effect of the market value, no convincing evidence is found: neither is there stronger evidence for insider trading, nor is the information processing slower for low MV companies.

Growth companies usually have a high market-tobook-value (MTBV) ratio. It can be hypothesized that growth companies have weaker corporate governance (allowing for more insider trading) and prices are subject to higher uncertainty (leading to slower information processing). To test this hypothesis, the sample is split into two parts according to MTBV. Among the 536 events there are 251 in the low MTBV group and 285 in the high MTBV group. Thus the high MTBV companies seem to publish financial information more often. The separation according to MTBV and MV leads to subsamples having similar compositions (Tables A1 and A2). This is the reason for similar results obtained for high MTBV and MV or the low MTBV and MV subsamples. Therefore, the MTBV case is not discussed in detail. Although in general the results are similar to the results obtained by the separation according to MV, there is a considerable difference in cumulated returns. The low MV companies have much higher returns than the high MV companies. This is not observed in the MTBV case. The six companies that are part of the high MTBV group must be relatively responsive to financial information compared to the companies replacing them in the high MV group. The speed of information processing and the extent of the reaction to news of the two MTBV subgroups appear to be similar, as can be seen in Figure 3. This provides some evidence

Figure 3: Cumulated Returns for Financial Statement Events - Low vs. High MTBV

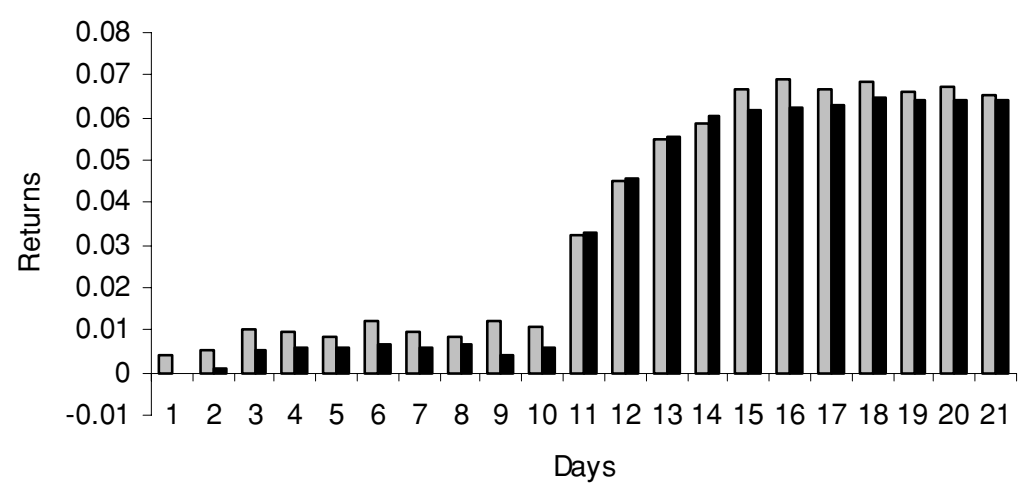

$\square$ Low MTBV $\square$ High MTBV 
against the hypothesis that low MTBV companies process information faster. Unlike in the low MV case, low MTBV companies build up an abnormal return in the PEW that is significant at the $10 \%$ level, but as in the low MV case volume changes are ambiguous, giving no clear evidence for insider trading.

This far there was no difference made between the content of published financial statements. In the following the sample events are divided into the categories: Annual report, $3^{\text {rd }}$ quarterly report (Q3), $2^{\text {nd }}$ quarterly report $(\mathrm{Q} 2)$ and $1^{\text {st }}$ quarterly (Q1) report. Additionally, there are categories for sales publications and tentative disclosures for every quarter. Finally, one category contains special events such as earnings warnings, the release of additional accounting data, etc. All in all there are 13 different categories. Most of the economic information content is in the reports themselves. Additionally, the sales and the tentative disclosure events do not contain many observations and are consequently not discussed. The subsamples are studied to find systematic differences in price and volume reactions to the release of the different reports.

For the base case (Table 1), the classification of the events reveals that the larger part of the $3^{\text {rd }}$ day significant return can be attributed to the release of annual and Q2 reports. This could be a result of earnings previews as they are often given out by financial analysts a few days before earnings announcements. If this is the case, financial analysts would have predictive power and investors would trade on this information. This could be evidence for financial managers creating value. However, such an argumentation needs a stronger backing by empirical work and could be a topic of future research.

The significant overall return in the PEW disappears for all event types, possibly because of a lower power of the statistical tests in the subsamples. Looking at the significant post-announcement returns, one can compare how long it takes for the different events to process information.
According to abnormal daily returns, the information processing for Q3 is the fastest and least significant one of all regular reports. Therefore, the financial statements of Q3 seem to contain the least information. Looking at the abnormal returns on the day of the disclosure, one can see that they are the smallest for Q1 and the largest for Q2 data. It seems to be the most beneficial to trade on Q2 insider information. Interestingly, the volume statistics for the PEW show that, for the overall sample, the volume dries out before positive events and increases before negative events. However, it turns out that volume decreases for most report types and news contents.[10] This indicates that investors wait with the repositioning of their portfolios until new information is revealed. Only for Q2 reports there is a highly significant volume increase for both statistics used in the negative event subsample. For the overall sample there is a significant increase for the non-parametric test. This is evidence for higher speculation before the announcement of Q2 information, possibly because of the anticipated strong price movements. The abnormal returns on day three are not accompanied by significantly positive abnormal volumes. Although there are significantly positive returns in the PEW, volume gives only weak signals and thus evidence for insider trading is weak for all event types. Looking at the daily volumes after the event, the low information content of Q3 reports is confirmed. Similarly there is a short period of abnormal volumes for Q1 reports as well.

Looking again at the small MV subsample, it is obvious that the observed significant abnormal return on day three of small companies is caused by annual and Q2 reports. For the overall PEW there is no evidence for significant abnormal returns for all different types of events. The significant abnormal returns for the different information releases last just as long as for the respective information release in the base case. The volume statistics show the same result as for the overall low MV subsample. For the releases of annual reports of low MV companies, the abnormal daily vol- 
umes last exceptionally long, being one of the drivers for abnormal daily volumes of the overall low MV sample. The third day abnormal returns are not supported by a significant increase in daily volume. Hence, the results for the low MV companies in general are not driven by single event types.

For high MV companies the information processing takes just as long as for the respective release in the base case. Thus, the speed of information processing does not seem to be dependent on the market value of a company. For Q1 and Q3 reports the abnormal returns on the announcement day are lower for high MV companies than for low MV companies. This could be caused by more information being available for high MV companies at a more constant rate over time. Thus, the information content of Q1 and Q3 reports would not be that large for high MV companies. In contrast, it could also be because returns behave more volatile for low MV companies. For all event types except Q2 reports, volume dries out for large MV companies before the release of accounting data (neglecting special reports). Similar to the base case, there is an increased volume before Q2 releases, possibly caused by an expected strong price reaction. This result of the base case seems to be driven by high MV companies and negative report releases. The volumes after the news release behave similar to the base case. The information processing is faster though for Q1 and Q3 reports, indicating a lower information content of those news for large MV companies. The results are mostly in line with the results for different reports in the whole sample, finding neither strong evidence for insider trading nor significantly different information processing. All those analyses are repeated with different values for the IPP, indicating robust results.

The results for the release of special information have not been discussed so far. One reason is the very limited statistical power of the tests applied in a small sample with only seven events.[11] The t-test indicates a volume increase at a significance level of $10 \%$ without significant abnormal returns, which is attributed to an information leakage. In the post-event window, a large number of negative returns is observed, reversing the strong abnormal returns on the event day and thereafter. This mean-reversion effect in the prices causes a significant value for $\theta_{3}$ and is evidence for an overreaction of investors when important additional information reaches the market. For high MV companies, on the day before the announcement there is a close-to-significant return $\left(\theta_{2}: \mathrm{t}\right.$-stat $\left.=1.64\right)$ in the same direction as the return on the announcement date. Furthermore the tests statistics $\theta_{4}$ and $\theta_{5}$ indicate an increased trade volume in the PEW. Thus, there is some weak evidence for insider trading activity on the information that is about to be released. Although the results for this last event type are fairly interesting, they have to be interpreted carefully because of the low number of observations even though the parametric tests are constructed to deliver good results even with a small number of events. The strong results can be attributed partially to a large price drop of Leica and UBS upon the release of an earnings warning.

\subsection{Corporate Control Actions}

This chapter summarizes the results for the effects of corporate control actions on the excess returns and the trading volume. In the sample there are 206 corporate control events. For the returns in the overall pre-event period, there are no clear signals in the base case, as summarized in Table 4, indicating that the news came by surprise. Regarding the effects of acquisitions daywise, the results remain noisy. The only interesting day is the fourth day before a corporate control announcement, having significant abnormal returns close to the $5 \%$ level. As expected, the event day itself contains significant abnormal returns. Depending on the chosen IPP, it takes the market at least 2 days (on a 5\% significance level or 3 days on a 
Table 4: Corporate Control - Base Case

\begin{tabular}{|c|c|c|c|c|}
\hline $\begin{array}{l}\text { Eventtype } \\
\text { Frequency } \\
\end{array}$ & $\begin{array}{c}\text { All Events } \\
206 \\
\end{array}$ & $\begin{array}{c}\text { Completed } \\
122 \\
\end{array}$ & $\begin{array}{c}\text { Bid } \\
7 \\
\end{array}$ & $\begin{array}{c}\text { Sale } \\
50\end{array}$ \\
\hline \multicolumn{5}{|l|}{ Results for the Returns } \\
\hline \multicolumn{5}{|l|}{ Test Statistics } \\
\hline Returns $\left(\theta_{1}\right)$ & 0.3704 & -0.4239 & 1.1503 & 1.5601 \\
\hline Returns Positive $\left(\theta_{1}\right)$ & 0.7047 & -0.0801 & 1.3114 & 1.6065 \\
\hline Returns Negative $\left(\theta_{1}\right)$ & 0.2499 & 0.5541 & -0.3165 & -0.3610 \\
\hline Ret. Before/After $\left(\theta_{3}\right)$ & 1.0340 & 1.0014 & 0.8290 & 1.0823 \\
\hline \multicolumn{5}{|c|}{ Daywise Abnormal Returns } \\
\hline 1 & -0.0018 & -0.0023 & 0.0153 & -0.0009 \\
\hline 2 & 0.0005 & 0.0017 & -0.0020 & -0.0012 \\
\hline 3 & -0.0008 & -0.0031 & -0.0069 & 0.0039 \\
\hline 4 & $0.0031^{*}$ & 0.0024 & 0.0086 & 0.0025 \\
\hline 5 & 0.0013 & 0.0004 & 0.0118 & 0.0030 \\
\hline 6 & -0.0001 & 0.0027 & $-0.0254^{* *}$ & -0.0011 \\
\hline 7 & 0.0003 & -0.0005 & 0.0137 & 0.0006 \\
\hline 8 & -0.0021 & $-0.0055^{\star *}$ & 0.0061 & 0.0032 \\
\hline 9 & 0.0004 & -0.0017 & 0.0043 & 0.0046 \\
\hline 10 & 0.0010 & 0.0031 & 0.0101 & 0.0003 \\
\hline 11 & $0.0098^{* *}$ & $0.0107^{* *}$ & -0.0107 & $0.0120^{* *}$ \\
\hline 12 & $0.0096^{* *}$ & $0.0095^{* *}$ & $0.0178^{*}$ & $0.0092^{* *}$ \\
\hline 13 & $0.0086^{\star *}$ & $0.0106^{* \star}$ & 0.0005 & $0.0095^{\star *}$ \\
\hline 14 & $0.0070^{* *}$ & $0.0056^{* *}$ & 0.0099 & $0.0077^{* *}$ \\
\hline 15 & $0.0065^{* *}$ & $0.0058^{* *}$ & 0.0020 & $0.0055^{*}$ \\
\hline 16 & $-0.0027^{*}$ & -0.0033 & -0.0005 & -0.0006 \\
\hline 17 & -0.0008 & -0.0014 & 0.0077 & -0.0013 \\
\hline 18 & 0.0012 & 0.0010 & 0.0026 & 0.0005 \\
\hline 19 & 0.0003 & -0.0012 & 0.0003 & 0.0021 \\
\hline 20 & 0.0013 & 0.0010 & 0.0067 & -0.0001 \\
\hline 21 & $-0.0041^{* *}$ & $-0.0047^{* *}$ & $-0.0212^{\star *}$ & -0.0013 \\
\hline \multicolumn{5}{|c|}{ Cumulated Abnormal Returns } \\
\hline 1 & -0.0018 & -0.0023 & 0.0153 & -0.0009 \\
\hline 2 & -0.0012 & -0.0006 & 0.0133 & -0.0021 \\
\hline 3 & -0.0020 & -0.0037 & 0.0064 & 0.0018 \\
\hline 4 & 0.0010 & -0.0013 & 0.0150 & 0.0043 \\
\hline 5 & 0.0023 & -0.0009 & 0.0268 & 0.0073 \\
\hline 6 & 0.0022 & 0.0019 & 0.0014 & 0.0062 \\
\hline 7 & 0.0025 & 0.0013 & 0.0151 & 0.0068 \\
\hline 8 & 0.0004 & -0.0042 & 0.0212 & 0.0100 \\
\hline 9 & 0.0008 & -0.0059 & 0.0255 & 0.0146 \\
\hline 10 & 0.0018 & -0.0027 & 0.0356 & 0.0150 \\
\hline 11 & 0.0116 & 0.0079 & 0.0249 & 0.0269 \\
\hline 12 & 0.0212 & 0.0174 & 0.0427 & 0.0361 \\
\hline 13 & 0.0298 & 0.0280 & 0.0432 & 0.0457 \\
\hline 14 & 0.0369 & 0.0336 & 0.0531 & 0.0534 \\
\hline 15 & 0.0433 & 0.0394 & 0.0551 & 0.0589 \\
\hline 16 & 0.0406 & 0.0361 & 0.0545 & 0.0583 \\
\hline 17 & 0.0398 & 0.0347 & 0.0622 & 0.0570 \\
\hline 18 & 0.0409 & 0.0358 & 0.0649 & 0.0575 \\
\hline 19 & 0.0413 & 0.0346 & 0.0652 & 0.0596 \\
\hline 20 & 0.0426 & 0.0356 & 0.0719 & 0.0595 \\
\hline 21 & 0.0385 & 0.0308 & 0.0507 & 0.0582 \\
\hline
\end{tabular}


Table 4: Corporate Control - Base Case (cont.)

\begin{tabular}{|c|c|c|c|c|}
\hline $\begin{array}{l}\text { Eventtype } \\
\text { Frequency } \\
\end{array}$ & $\begin{array}{c}\text { All Events } \\
206 \\
\end{array}$ & $\begin{array}{c}\text { Completed } \\
122 \\
\end{array}$ & $\begin{array}{c}\text { Bid } \\
7 \\
\end{array}$ & $\begin{array}{c}\text { Sale } \\
50 \\
\end{array}$ \\
\hline \multicolumn{5}{|l|}{ Results for the Volume } \\
\hline $\begin{array}{l}\text { Non-parametric Test }\left(\theta_{5}\right) \\
\text { T-test }\left(\theta_{4}\right) \\
\text { Non-par. Test Positive }\left(\theta_{5}\right) \\
\text { T-test Positive }\left(\theta_{4}\right) \\
\text { Non-par. Test Negative }\left(\theta_{5}\right) \\
\text { T-test Negative }\left(\theta_{4}\right) \\
\end{array}$ & $\begin{array}{r}1.3220 \\
0.2601 \\
0.4698 \\
-0.6116 \\
1.4667 \\
0.9461 \\
\end{array}$ & $\begin{array}{r}0.1718 \\
0.3367 \\
0.3753 \\
0.0540 \\
-0.1771 \\
0.3999 \\
\end{array}$ & $\begin{array}{l}3.3466 \\
0.8094 \\
1.8257 \\
0.7385 \\
2.8460 \\
0.3451 \\
\end{array}$ & $\begin{array}{r}0.1789 \\
-0.5073 \\
0.7593 \\
-1.7100 \\
-0.7906 \\
0.9028 \\
\end{array}$ \\
\hline \multicolumn{5}{|c|}{ Hypothesis Test of Daywise Volume $\left(\theta_{6}\right)$} \\
\hline 1 & -0.6967 & -0.3621 & 1.1339 & -1.1314 \\
\hline 2 & -0.9754 & -0.5432 & 1.1339 & -1.4142 \\
\hline 3 & 0.9754 & 0.9054 & 0.3780 & -0.2828 \\
\hline 4 & 0.1393 & 0.1811 & 1.1339 & 0.0000 \\
\hline 5 & -0.2787 & -0.1811 & 1.8898 & -0.8485 \\
\hline 6 & 1.1148 & -0.1811 & 2.6458 & 1.1314 \\
\hline 7 & 2.5082 & 1.2675 & -1.8898 & 2.2627 \\
\hline 8 & 0.6967 & 0.9054 & 1.1339 & -0.5657 \\
\hline 9 & 0.8361 & -0.1811 & 2.6458 & 0.2828 \\
\hline 10 & -0.1393 & -1.2675 & 0.3780 & 1.1314 \\
\hline 11 & 4.1804 & 2.1729 & -0.3780 & 3.6770 \\
\hline 12 & 3.4837 & 1.9918 & 0.3780 & 3.6770 \\
\hline 13 & 2.0902 & 1.6296 & -1.1339 & 2.5456 \\
\hline 14 & -0.1393 & 0.0000 & -0.3780 & 0.2828 \\
\hline 15 & 0.0000 & 0.1811 & -1.1339 & -0.2828 \\
\hline 16 & -1.2541 & -0.9054 & -0.3780 & -1.1314 \\
\hline 17 & -0.6967 & -1.0864 & -0.3780 & -0.2828 \\
\hline 18 & 0.6967 & 0.3621 & -1.8898 & 1.4142 \\
\hline 19 & 1.8115 & 0.5432 & 1.1339 & 1.6971 \\
\hline 20 & -0.5574 & -0.9054 & -0.3780 & 0.8485 \\
\hline 21 & -0.1393 & -0.5432 & 0.3780 & 0.2828 \\
\hline
\end{tabular}

The table shows in the columns the results for the different event types of the base case. In the first section the results of the $\mathrm{t}$-tests on the abnormal returns are reported, whereas positive stands for the positive events subsample and negative for the negative events subsample. In the second part the daily abnormal returns are shown. **: Significance level of $5 \%$, *: Significance level of $10 \%$. The gray line emphasizes the day of the information release. The third section contains the cumulated abnormal returns, starting on day one. In the fourth section the results for the tests on abnormal volume are shown. The last section contains the results for the non-parametric tests on daily abnormal volume.

$10 \%$ level) of abnormal returns to process the information. Afterwards we experience no significant price change except one significant $(2.64$ standard deviations) negative return on day 21. Interestingly, this strong negative return can be observed for most of the alternate cases and different corporate control events. This significant negative return and the significant positive return on the event day itself indicates a mean reversion effect in the price adjustment after a corporate control announcement similarly to the one observed in the last section. This effect could be interpreted as an overreaction of investors after the announcement.

The volume in the pre-event period of 10 days stays relatively constant. If this window is shortened to only five days, there is a significant positive abnormal volume deviation that can be meas- 
ured by the t-test as well as by the non-parametric test. Thus, there is a reaction in the volume, but not in the return. Since acquisition announcements are a surprise to the market, the increased volume is an unexpected finding given the hypothesis of no insider trading. This volume reaction might be attributed to market rumors, which lead to higher trading activity without giving the stock price any clear direction. The daily volume is above the median level for two days after the event. Thus returns and volumes suggest that new information does not get processed right away. Compared to financial information, the processing is faster and has a lower price impact, indicating a lower information content.

The introduction of a hurdle rate of $4 \%$ results for the corporate control case in a fairly small sample of only 18 observations (results are not reported here). Thus results have to be interpreted carefully. The results give no clear evidence for faster information processing of this subgroup of events as it might be caused by a larger media attention. A price run-up before the release can be seen, but is not significant. After the new information is processed into prices, a trend sets in reversing the price movement upon the release of the information. This could be evidence for a mean reversion effect after strong price movements caused by an overreaction. For daily volumes nothing can be said because of the low number of observations.

The complete analysis of low and high MV companies is not reported for the sake of brevity. For the low MV companies in the corporate control case, there is no evidence for systematic trading in the PEW. Neither are there significant abnormal returns, nor is there a significant change in volume. Except on day four for the high MV companies, there is no significantly positive return in the PEW (daywise and cumulated) as well. Furthermore, high MV companies are the only ones that have a significant abnormal volume, overall and for negative events. This suggests the existence of an information leakage and could be evidence for insider trading, but it is not very strong. The intensity of information processing actually seems to be different since in Figure 4 the change in price is more pronounced for low than for large MV companies. This finding is consistent with the assumptions about the processing of information in low MV companies. The time needed for information

Figure 4: Cumulated Returns for Corporate Control Events - Low vs. High MV

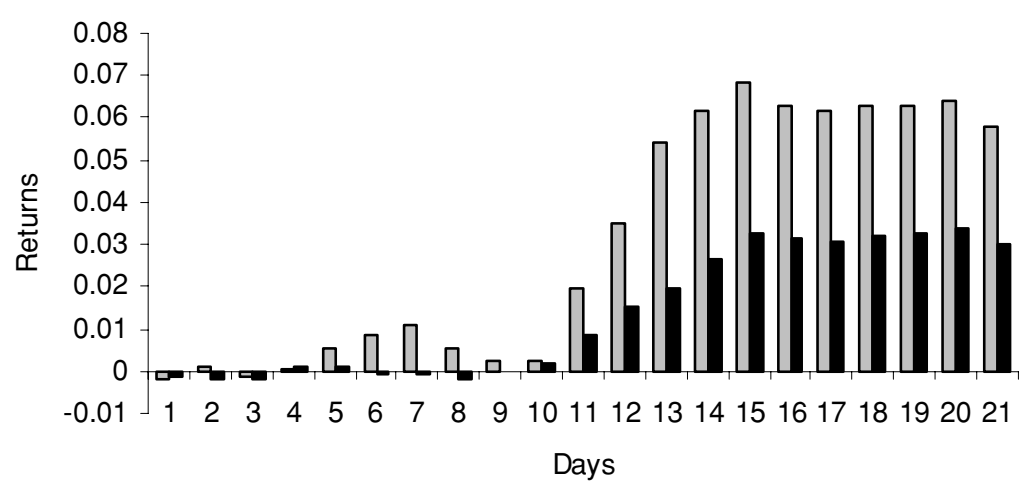

$\square$ Low MV $\square$ High MV 
Figure 5: Cumulated Returns for Corporate Control Events - Low vs. High MTBV

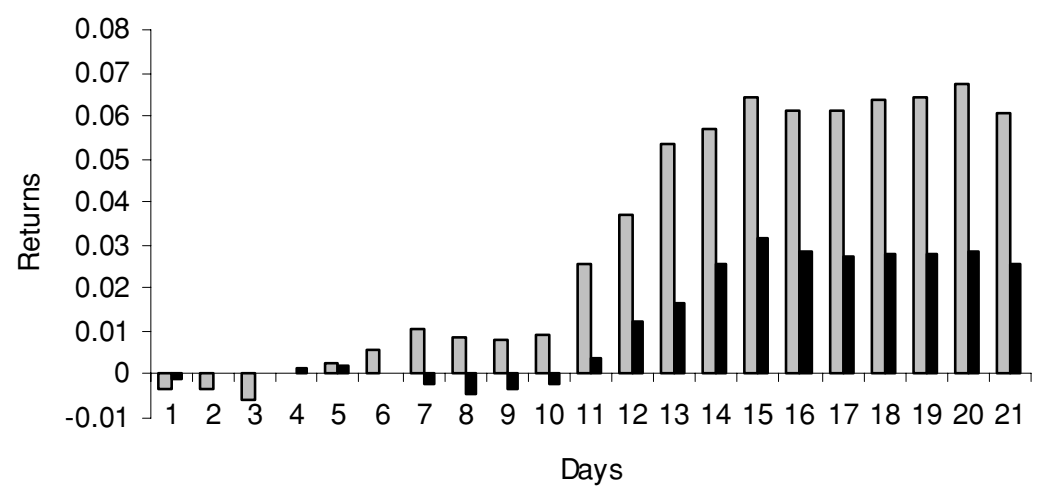

$\square$ Low MTBV $\square$ High MTBV

processing as indicated by significant abnormal returns is the same for the two subsamples. For daily abnormal volumes after the event there are no clear signals.

The hypothesis that high market-to-book-value companies (MTBV) are growth companies with slow information processing and a higher insider trading activity is also tested for corporate control events. The results suggest that the hypothesis does not hold true since the predicted effects cannot be identified. The majority of events - about $63.6 \%$ - is in the sample of companies with high MTBV, which includes the larger companies, seeming to be more active on the corporate control market. The results are very close to the MV subsamples results and thus the MTBV subsamples are not discussed in detail. Looking at the cumulated returns, the results for the MTBV subsamples are now much closer to the respective MV group than they are in the financial statements section (Figures 4 and 5). Thus the MV and the MTBV groups and the corresponding events seem to be even more similar once corporate control actions are considered. The cumulated returns show that the overall effect of the news release is much larger for low MTBV firms.
Corporate control actions are much more at the discretion of the management than the earnings announcements. Assuming that the management is acting in the interest of the shareholders, they only do corporate control actions that increase the value of the company. It could therefore be assumed that the announcement of a corporate control action has a positive impact on the economic success of a company - at least in the long run. In this case, all these announcements should have a positive impact on the price and one does not have to distinguish between good and bad news anymore. However, the previous results are confirmed. In the base case, the statistics for the overall PEW are insignificant with the exception of the $5^{\text {th }}$ day of the PEW. On the announcement day and the two days thereafter, there are significant positive returns. This confirms that the market takes some time to process the information. Another point that can be made through this modification is that the used approach to identify positive and negative events does not cause a large bias of the results. The results are fairly stable with respect to a change in the selection criteria. 
Up to now we did not distinguish between different types of events. To have a closer look at different types of control actions, the dataset is divided into completed acquisitions (completed), bids for companies (bid) and divestitures (sale). The problem with these subsets is that the number of observations becomes small. The corporate control events of the company Holcim are not included in the subsample because Holcim published a large number of press releases with very little news content. By including these events, the small subsamples would have been biased towards an inability to discard the null hypothesis of no effect of corporate control events on the stock price and the volume. Most of the reported corporate control events are completed buy transactions. For these events, similar results hold true as for the complete sample. For the bids there are not enough observations for drawing any significant conclusions. For divestiture announcements there are interesting results und enough observations to draw conclusions. For the 50 sales in the base case sample there are close to significant cumulative abnormal returns in the PEW of a divestiture. This is mainly due to the positive divestiture events. The evidence for abnormal returns during the PEW is dominated by a close-to-significant return on day nine. However, there are no significant abnormal volumes on that day. For the modifications of the base case (MV and hurdle rate analysis), the cumulated returns of sales in the PEW are predominantly positive and sometimes significantly positive at the $5 \%$ level. This is some evidence for insider trading on divestiture events. However, this evidence is not supported by increased volume. If anything, the volume is decreasing for the base case and the modifications. But there is no clear evidence for either one. This indicates that the abnormal returns are not caused by a higher trading activity and a subsequent price change. The abnormal returns could result from new information arriving at the market before the announcement. If market participants interpret the new information in the same way, prices might change with low volume. Previous trading activities of insiders could bring this new information to the market. Another explanation for this could be that volume drops because noise traders wait for new informa-

Figure 6: Cumulated Returns for the Base Cases

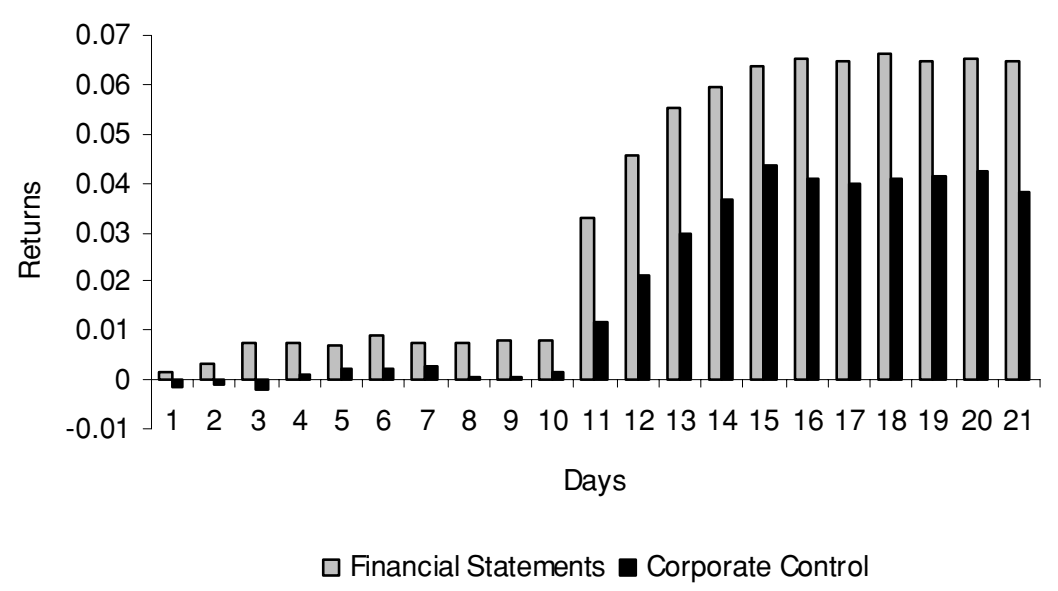


tion to arrive after rumors. Then insiders enter the market, offsetting the liquidity decrease caused by noise traders waiting for new information only partially. The information processing in the base case takes three to five days - depending on the chosen IPP. This is just as long as the significantly abnormal positive volumes persist. These numbers are in line with the results for the base case of the entire sample.

The analysis in this section does not find any compelling evidence for insider trading. There are some hints for abnormal returns, possibly due to insider trading. But they are not accompanied by increased volume, making the interpretation difficult. The information processing is slower than expected in an efficient market. For most of the cases it takes between two to five days to incorporate the news into the prices. In a semi-strong efficient capital market, prices would fully adjust to new information immediately. The long information processing period provides some evidence that the Swiss capital market is not efficient according to the semi-strong form. News are not reflected fully in prices right after their release, opening up possibilities for profitable trades on stale information. This finding shows that the gathering and analysis of information can generate value in the Swiss equity market. The impact of corporate control news on the price is, in general, less pronounced than the impact of financial statements releases. Figure 6 illustrates this finding for the two base cases.

\section{Conclusions}

For the first time, an event study investigating the processing of information and the existence of insider trading on the Swiss stock market is conducted. Although Swiss laws are less restrictive than those of other countries, the event study methodology used in this paper does not uncover systematic insider trading before the publication of information. Even for information producing large returns upon publication, no significant runup returns can be detected. Interestingly, significant abnormal returns are found on day three and four of the pre-event window. Earnings previews by financial analysts could be a possible explanation for this effect. In general, the volume before publications of earnings figures decreases according to the non-parametric test. This liquidity dryout is attributed to investors waiting for new information to arrive before trading. The volume changes before the publication of a corporate control action are noisier than the corresponding statistic for the financial statements, indicating that, in general, acquisition announcements come by surprise. The publication of financial and corporate control news triggers larger price movements for companies with low market values.

Regarding the processing of information, the Swiss market appears to be rather slow in incorporating new information into stock prices. We find significantly abnormal returns for about two to four days after the release of new financial information or announcements of corporate control actions. Although this appears to be a fairly long period of time, similar results have been found for other markets. For releases of financial statements with large price effects, faster information processing is found than for less important news. The market value of a firm seems to have only a limited impact on the speed of information processing. However, consistent with the existing literature, the price impact of earnings announcements is larger for small-value firms. 


\section{APPENDIX}

\section{Table A1: Companies in Low and High MV Groups}

\begin{tabular}{lrlr}
\hline LOW & & HIGH & 8712.1 \\
\hline Belimo Holding & 312.0 & ABB & 2573.3 \\
Crealogix Holding & 57.5 & Actelion & 2641.3 \\
Day Software Holding & 16.5 & Atel & 1054.7 \\
Feintool & 97.9 & Barry Callebaut & 865.8 \\
Gavazzi & 22.8 & Bobst Group & 6520.6 \\
Graubündner Kantonalbank & 178.2 & Ciba SC & 2738.9 \\
Hügli Holding & 55.6 & Clariant International & 615.4 \\
Industrieholding Cham & 183.0 & Compagnie Financiere Tradition & 10864.0 \\
Interroll Holding & 107.6 & Holcim & 527.5 \\
LEM & 72.0 & Jelmoli Holding & 430.6 \\
MCH Messe Schweiz & 64.9 & Leica Geosystems Holding & 120047.1 \\
Mobilezone Holding & 77.3 & Nestle & 137144.9 \\
Phoenix Mecano Management & 357.5 & Novartis & 546.0 \\
Schaffner & 130.8 & Schweiz. Nat.-Versicherungs-Ges. & 5717.9 \\
Schweiter Technologies & 205.7 & SGS Surveillance & 1075.5 \\
Sia Abrasives Holding & 172.5 & Sika & 1069.6 \\
Swiss Small Cap Invest & 24.8 & Sulzer & 4912.4 \\
Swisslog Holding & 106.3 & Swiss Life Holding & 26988.5 \\
Think Tools & 14.3 & Swiss Re & 12942.2 \\
Unilabs & 190.0 & Synthes-Stratec & 93523.4 \\
Züblin Immobilien Holding & 259.8 & UBS &
\end{tabular}

The table shows the market values of the respective companies in millions of CHF provided by Datastream as of 10/23/2003. 
Table A2: Companies in Low and High MTBV Groups

\begin{tabular}{lllr}
\hline LOW & & HIGH & -3.31 \\
\hline Bobst Group & 1.20 & ABB & 18.64 \\
Crealogix Holding & 1.04 & Actelion & 3.55 \\
Day Software Holding & 0.73 & Atel & 3.57 \\
Feintool & 1.03 & Barry Callebaut & 3.53 \\
Gavazzi & 0.74 & Belimo Holding & 2.86 \\
Graubündner Kantonalbank & 0.18 & Ciba SC & 6.44 \\
Hügli Holding & 1.36 & Clariant International & 3.70 \\
Industrieholding Cham & 1.07 & Compagnie Financiere Tradition & 11.79 \\
Jelmoli Holding & 1.19 & Holcim & 2.84 \\
LEM & 1.50 & Interroll Holding & 9.77 \\
MCH Messe Schweiz & 0.46 & Leica Geosystems Holding & 5.13 \\
Phoenix Mecano Management & 2.13 & Mobilezone Holding & 23.59 \\
Schweiter Technologies & 1.90 & Nestle & 4.45 \\
Schweiz. Nat.-Versicherungs-Ges. & 0.97 & Novartis & 5.03 \\
Sia Abrasives Holding & 1.63 & Schaffner & 7.79 \\
Sika & 2.31 & SGS Surveillance & 4.26 \\
Sulzer & 1.22 & Swiss Re & -1.02 \\
Swiss Life Holding & 1.74 & Swisslog Holding & 7.83 \\
Swiss Small Cap Invest & 0.74 & Synthes-Stratec & 4.08 \\
Think Tools & 0.50 & UBS & -8.25 \\
Züblin Immobilien Holding & 0.66 & Unilabs &
\end{tabular}

The table shows the market-to-book ratios provided by Datastream as of 10/23/2003. The negative market-to-book ratios are caused by adjustments for intangibles by Datastream. Because negative market-to-book ratios imply a negative adjusted book value, the difference between book and market value is even larger than for high market-to-book firms. Therefore, they are also categorized as high market-to-book firms. 


\section{STATISTICAL APPENDIX}

The statistic $\theta_{1}$ tests if there are systematic and significant abnormal returns in the PEW. One approach towards this is to determine the cumulative abnormal return of an event during the PEW, i.e.,

$\operatorname{CAR}\left(T_{1}, \tau\right)=\sum_{t=T_{1}}^{\tau-1} A R_{t, t}$,

with variance

$\sigma_{i}^{2}\left(T_{1}, \tau\right)=\left(\tau-T_{1}\right) \sigma_{\varepsilon_{i}}^{2}$

The variance is being calculated for a period of 30 days before the PEW opens and is subject to stress testing in robustness checks for the results of the study. The abnormal return can then be averaged over all events in the sample, i.e.,

$\overline{C A R}\left(T_{1}, \tau\right)=\frac{1}{N} \sum_{i=1}^{N} C A R_{i}\left(T_{1}, \tau\right)$

According to central limit theory this average is approximately normally distributed. Assuming that the abnormal returns of the events are uncorrelated, the variance of the average cumulative abnormal return is given by

$$
\operatorname{var}\left(\overline{C A R}\left(T_{1}, \tau\right)\right)=\frac{1}{N^{2}} \sum_{i=1}^{N} \sigma_{i}^{2}\left(T_{1}, \tau\right)
$$

Now a standard t-test with the null hypothesis of no insider trading can be performed:

$$
\theta_{I}=\frac{\overline{C A R}\left(T_{1}, \tau\right)}{\sqrt{\operatorname{var}\left(\overline{C A R}\left(T_{1}, \tau\right)\right)}} .
$$

The statistic $\theta_{2}$ can be used to test for significant abnormal returns on special days before the event. For $\theta_{2}$ the average abnormal returns for a specific day in the event window are calculated and the average for all events is taken, i.e.,

$$
\overline{A R}\left(T^{*}\right)=\frac{1}{N} \sum_{i=1}^{N} A R_{i}\left(T^{*}\right),
$$

with $\mathrm{T}^{*} \in\left[\mathrm{T}_{1}, \mathrm{~T}_{2}\right]$. The resulting variance can be specified by

$$
\operatorname{var}\left(\overline{A R}\left(T^{*}\right)\right)=\frac{1}{N^{2}} \sum_{i=1}^{N} \sigma_{\varepsilon_{i}}^{2}\left(T^{*}\right) .
$$

resulting in the following test statistic:

$\theta_{2}=\frac{\overline{A R}\left(T^{*}\right)}{\sqrt{\operatorname{var}\left(\overline{A R}\left(T^{*}\right)\right)}}$.

$\theta_{2}$ can also be applied for testing for abnormal returns in the post-event window using $\mathrm{T}^{*} \in\left[\tau, \mathrm{T}_{2}\right]$.

The third test used for abnormal returns is termed $\theta_{3}$ and is derived as follows:

$$
\begin{aligned}
& C A R_{i}^{p r e}\left(T_{1}, \tau, p\right)=\sum_{t=T_{+}^{+} p}^{\tau-1} A R_{i, t}, \\
& C A R_{i}^{\text {post }}\left(T_{2}, \tau, p\right)=\sum_{t=\tau+p+p+1}^{T_{2}} A R_{t, t}, \\
& \overline{C A R}^{\text {ree }}\left(T_{1}, \tau, p\right)=\frac{1}{N} \sum_{i=1}^{N} C A R_{i}^{\text {pre }}\left(T_{1}, \tau, p\right), \\
& \overline{C A R}^{\text {post }}\left(T_{2}, \tau, p\right)=\frac{1}{N} \sum_{i=1}^{N} C A R_{i}^{\text {post }}\left(T_{2}, \tau, p\right), \\
& \sigma_{i}^{2}\left(T_{1}, \tau, p\right)^{p r e}=\left(\tau-T_{1}-p\right) \sigma_{\varepsilon_{i}, p r e}^{2}, \\
& \sigma_{i}^{2}\left(T_{2}, \tau, p\right)^{\text {post }}=\left(T_{2}-\tau-p\right) \sigma_{\varepsilon_{i}, p o s t}^{2}, \\
& \operatorname{var}^{p r e}\left(\overline{C A R}^{p r e}\left(T_{1}, \tau, p\right)\right)=\frac{1}{N^{2}} \sum_{j=1}^{N} \sigma_{i}^{2}\left(T_{1}, \tau, p\right) \text {, } \\
& \operatorname{var}^{\text {post }}\left(\overline{C A R}^{\text {post }}\left(T_{2}, \tau, p\right)\right)=\frac{1}{N^{2}} \sum_{i=1}^{N} \sigma_{i}^{2}\left(T_{2}, \tau, p\right) \text {, } \\
& \theta_{3}=\frac{\overline{C A R}^{\text {pre }}\left(T_{1}, \tau, p\right)-\overline{C A R}^{\text {post }}\left(T_{2}, \tau, p\right)}{\sqrt{\operatorname{var}^{\text {pre }}\left(\overline{C A R}^{\text {pre }}\left(T_{1}, \tau, p\right)\right)+\operatorname{var}^{\text {post }}\left(\overline{C A R}^{\text {post }}\left(T_{2}, \tau, p\right)\right)}} .
\end{aligned}
$$

The statistic $\theta_{3}$ is used to test for a difference in the pattern of average cumulated abnormal returns before and after the event.

For the analysis of trade volume changes two tests are used. $\theta_{4}$ tests for a significant deviation of 
cumulated volume from its mean in the estimation window. Let $\mu_{\mathrm{e}, \mathrm{i}}$ and $\sigma_{\mathrm{e}, \mathrm{i}}{ }^{2}$ denote the mean and the variance of daily volume in the 30 day estimation period for event $i$. Then, under the null hypothesis of no insider trading activities before the event day, the expected value and the variance of cumulated volume $(\mathrm{CV})$ in the pre-event period of event $\mathrm{i}$ are as follows:

$$
\begin{gathered}
E\left(C V_{i}\right)=\left(\tau-T_{1}\right) \mu_{e, i}, \\
\operatorname{var}\left(C V_{i}\right)=\left(\tau-T_{1}\right) \sigma_{e, i}^{2} .
\end{gathered}
$$

Since

$$
C V_{i}=\sum_{t=\tau-T_{i}}^{\tau-1} V_{t, i}
$$

the test statistic becomes:

$$
\theta_{4}=\frac{\sum_{i=1}^{N} C V_{i}-\sum_{i=1}^{N} E\left(C V_{i}\right)}{\sqrt{\sum_{i=1}^{N} \operatorname{var}\left(C V_{i}\right)}} .
$$

The second approach tests if the volume in the PEW follows the same process as in the estimation period. If it follows the same process, $50 \%$ of daily volume should be above and $50 \%$ below the median calculated in the estimation period. If the volume is significantly more than $50 \%$ above the median, then there is an indication that the trading pattern changes during the pre-event period. This might be a hint indicating the presence of insider trading. Following MACKINLAY (1997), the following statistic is constructed:

$$
\theta_{5}=\left(\frac{N_{\mathrm{Vol}}^{+}}{N_{\mathrm{Vol}}}-0.5\right) \frac{\sqrt{N_{\mathrm{Vol}}}}{0.5},
$$

where $\mathrm{N}_{\mathrm{vol}}$ stands for the total number of observations of daily trading volume during the pre-event windows of all events that are in the sample. $\mathrm{N}_{\mathrm{vol}}{ }^{+}$ indicates how often the daily trading volume in the pre-event windows of all events is higher than the respective median volume in the estimation period. 


\section{ENDNOTES}

[1] See studies by SEYHUN (1986, 1988, 1992), Jaffe (1974), MEULBROEK (1992), LAKONISHOK and LEE (1998), JENG et al. (2003) and others.

[2] See, for example, KIM and VERRECCHIA (1991) for a further discussion of this argument.

[3] The regressions performed for the empirical study deliver reasonable results. Betas are in the range between -0.16 and 1.76 with a mean of 0.58 . The mean of $R$-squared is 0.18 , whereas the $\mathrm{R}$-squared increases with market value.

[4] See, for example, MACKINLAY (1997).

[5] A similar procedure is used by GIVOLY and PALMON (1985).

[6] CHUNG and CHAROENWONG (1998) state that insider trading increases as firm size decreases.

[7] More information is available from www.huginonline.com.

[8] See, for example, studies by CONRAD and NIDEN (1992), MEULBROEK (1992), KEOWN and PINKERTON (1981).

[9] For a discussion of reasons for post-announcement drifts, see BERNARD and THOMAS (1989).

[10] BEAVER (1968) supports these results.

[11] The subsample consists of four earnings warnings, an announcement of record sales numbers, a correction of Q2 results and the additional publication of financial data. 


\section{REFERENCES}

AHARONY, J. and I. SWARY (1980): "Quarterly Dividend and Earnings Announcements and Stockholders' Returns: An Empirical Analysis", Journal of Finance, 35 (1), pp. 1-12.

BEAVER, W. (1968): "The Information Content of Annual Earnings Announcements", Journal of Accounting Research, 6 (3), pp. 67-92.

BERNARD, V. L. and J. THOMAS (1989): "PostEarnings-Announcement Drift: Delayed Price Response or Risk Premium?", Journal of Accounting Research, 27 (3), pp. 1-36.

CAMPBELL, J. Y., A. W. LO and A. C. MACKINLAY (1997): "The Econometrics of Financial Markets", Princeton, NJ: Princeton University Press.

CHEN, C. R., J. W. LIN and D. A. SAUER (1997): "Earnings announcements, quality and quantity of information, and stock price changes", Journal of Financial Research, 20 (4), pp. 483-502.

CHUNG, K. and C. CHAROENWONG (1998): "Insider Trading and the Bid-Ask Spread", Financial Review, 33 (3), pp. 1-20.

CONRAD, J. and C. M. NIDEN (1992): "Order flow, trading costs and corporate acquisition announcements", Financial Management, 21 (4), pp. 22-31.

DU, J. and S. WIE (2003): "Does Insider Trading Raise Market Volatility?", National Bureau of Economic Research Working Paper: 9541.

FERREIRA, E. J. and L. D. BROOKS (2000): "Rereleased Information in The Wall Street Journal's 'Insider Trading Spotlight' Column”, Quarterly Journal of Business \& Economics, 39 (1), pp. 22-34.

GIVOLY, D. and D. PALMON (1985): "Insider Trading and the Exploitation of Inside Information: Some Empirical Evidence", Journal of Business, 58 (1), pp. 6987.

HILLMER, S. C. and P. L. YU (1979): "The Market Speed of Adjustment to New Information", Journal of Financial Economics, 7 (4), pp. 321-345.

JAFFE, J. F. (1974): "The Effect of Regulation Changes on Insider Trading", Bell Journal of Economics and Management Science, 5 (1), pp. 93-121.
JAIN, P. C. (1988): "Response of Hourly Stock Prices and Trading Volume to Economic News", Journal of Business, 61 (2), pp. 219-231.

JENG, L. A., A. METRICK and R. ZECKHAUSER (2003): "Estimating the Returns to Insider Trading: A Performance-Evaluation Perspective", Review of Economics \& Statistics, 85 (2), pp. 453-471.

JENG, L. A., A. METRICK and R. ZECKHAUSER (1999): "The Profits to Insider Trading: A PerformanceEvaluation Perspective", National Bureau of Economic Research Working Paper: 6913.

JENNINGS, R. H. and C. B. BARRY (1983): "Information Dissemination and Portfolio Choice", Journal of Financial \& Quantitative Analysis, 18 (1), pp. 1-19.

KARPOFF, J. M. (1987): "The Relation between Price Changes and Trading Volume: A Survey", Journal of Financial \& Quantitative Analysis, 22 (1), pp. 109-126.

KEOWN, A. J. and J. M. PINKERTON (1981): "Merger Announcements and Insider Trading Activity: An Empirical Investigation", Journal of Finance, 36 (4), pp. 855-869.

KIM, O. and R. E. VERRECCHIA (1991): "Trading Volume and Price Reactions to Public Announcements", Journal of Accounting Research, 29 (2), pp. 302-21.

LAKONISHOK, J. and I. LEE (1998): "Are Insiders' Trades Informative?", National Bureau of Economic Research Working Paper: 6656.

LEE, C., B. MUCKLOW and M. READY (1993): "Spreads, depths, and the impact of earnings information: an intraday analysis", Review of Financial Studies, 6 (2), pp. 345-374.

LELAND, H. E. (1992): "Insider trading: Should it be prohibited?", Journal of Political Economy, 100 (4), pp. 859-887.

MACKINLAY, A. C. (1997): "Event studies in economics and finance", Journal of Economic Literature, 35 (1), pp. 13-39.

MEULBROEK, L. K. (1992): "An Empirical Analysis of Illegal Insider Trading”, Journal of Finance, 47 (5), pp. 1661-1699.

MORSE, D. (1981): "Price and Trading Volume Reaction Surrounding Earnings Announcements: A Closer 
Examination", Journal of Accounting Research, 19 (2), pp. 374-383.

SEYHUN, N. (1992): "Why does aggregate insider trading predict future stock returns?", Quarterly Journal of Economics, 107 (4), pp. 1303-1331.

SEYHUN, N. (1988): "The Information Content of Aggregate Insider Trading", Journal of Business, 61 (1), pp. 1-24.

SEYHUN, N. (1986): "Insiders' Profits, Costs of Trading, and Market Efficiency", Journal of Financial Economics, 16 (2), pp. 189-212.

SUOMINEN, M. (2001): "Trading Volume and Information Revelation in Stock Markets", Journal of Financial \& Quantitative Analysis, 36 (4), pp. 545-565.

SWISS EXCHANGE (1996): "Ad hoc-Publicity". 